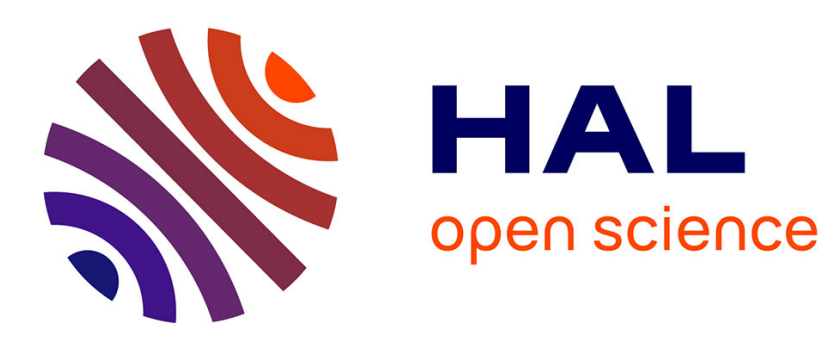

\title{
Financial Frictions and the Extensive Margin of Activity
} Jean-Christophe Poutineau, Gauthier Vermandel

\section{- To cite this version:}

Jean-Christophe Poutineau, Gauthier Vermandel. Financial Frictions and the Extensive Margin of Activity. 2015. halshs-01205497

\section{HAL Id: halshs-01205497 https://shs.hal.science/halshs-01205497}

Preprint submitted on 25 Sep 2015

HAL is a multi-disciplinary open access archive for the deposit and dissemination of scientific research documents, whether they are published or not. The documents may come from teaching and research institutions in France or abroad, or from public or private research centers.
L'archive ouverte pluridisciplinaire HAL, est destinée au dépôt et à la diffusion de documents scientifiques de niveau recherche, publiés ou non, émanant des établissements d'enseignement et de recherche français ou étrangers, des laboratoires publics ou privés. 


\title{
Financial Frictions and the Extensive Margin of Activity
}

\author{
Jean-Christophe Poutineau* Gauthier Vermandel ${ }^{\dagger}$
}

This version: September 25, 2015

\begin{abstract}
This paper evaluates the role of financial intermediaries, such as banks, on the extensive margin of activity. We build a DSGE model that combines the endogenous determination of the number of firms operating on the goods market with financial frictions through a financial accelerator mechanism. We more particularly account for the fact that the creation of a new activity partly requires loans to finance spendings during the setting period. This model is estimated on US data between 1993Q1 to 2012Q3. We get three main results. First, financial frictions play a key role in determining the number of new firms. Second, in contrast with real macroeconomic shocks (where investment in existing production lines and the creation of new firms move in the opposite direction), financial shocks have a cumulative effect on the two margins of activity, amplifying macroeconomic fluctuations. Third, the critical role of financial factors is mainly observed in the period corresponding to the creation of new firms. In the long run, the variance of the effective entry share is almost explained by supply shocks.
\end{abstract}

JEL classification: E31; E32; E52

Keywords: Extensive Margin; Financial Frictions; Financial Accelerator; DSGE model; Bayesian estimation

We thank Akbar Sadeghi of the US Bureau of Labor Statistics for providing data on firm's entry. We remain responsible for any errors and omissions.

${ }^{*}$ CREM, UMR CNRS 6211, Université de Rennes I, Rennes, France. E-mail: jeanchristophe.poutineau@univ-rennes1.fr.

${ }^{\dagger}$ Department of Economics, University Paris-Dauphine, Paris, France. E-mail: gauthier@vermandel.fr. 


\section{Introduction}

The creation of new firms is a key aspect of business cycles. This feature is now widely documented in the empirical literature and has given rise to a series of theoretical papers following the path-breaking contribution of Bilbiie et al. (2007). However, although financial decisions are a critical aspect of the creation of new activities, most of the existing literature on the extensive margin of activity assumes a marginal contribution of financial factors by neglecting the key role of banks.

The aim of this paper is to evaluate the effect of financial frictions on the extensive margin of activity. We more particularly investigate how the financial accelerator may have an impact on the creation of new firms. We build a Dynamic Stochastic General Equilibrium (DSGE) model that combines the endogenous determination of the number of firms with financial frictions giving rise to the financial accelerator. This model is estimated using recent developments of Bayesian econometrics on US data over a sample time period running from 1993Q1 to 2012Q3.

In this setting, the decision to create a new production unit emanates from both households and entrepreneurs. As new firms have to be built one period before the production of the new goods, entrepreneurs must borrow from financial intermediaries to finance part of the initial wage bill required to pay workers during the entry period. Thus, with respect to traditional DSGE models with financial frictions, we enlarge the financial constraint of entrepreneurs to account for the choice of investing limited resources either in the capital of existing firms or financing new production lines. As a consequence, both capital accumulation (that determines the intensive margin of activity) and firm entry (that determines the extensive margin of activity) are affected by financial frictions and financial shocks. We more particularly consider shocks to the net worth of entrepreneurs (that can be associated to fluctuations on the stock exchange) and to the mark up of banking activity (which deteriorates the lending conditions in the economy). In line with the solution introduced by Bilbiie et al. (2007), we assimilate the number of firms to the number of goods available for consumption. ${ }^{1}$

In this paper, we get three main results. First, we find that financial frictions play a critical role in replicating real world data. In particular a wage bill in advance constraint links the creation of firms to the lending conditions of the banking system. This friction is helpful to fix the problem observed in the original setting of Bilbiie et al. (2007) regarding the counterintuitive increase in the number of new firms following an increase in the interest rate. We find that bank lending conditions play a key role as a transmission channel for monetary policy shocks to get a standard drop in the number of firm creation following a restrictive monetary policy decision. In our financial environment the creation of new firms by entrepreneurs depends on an interest rate set by the banking system and no longer on the sole policy rate set by the monetary authorities.

Second, the need to finance investment in existing firms and the creation of new goods' varieties with bank loans affect the dynamics of the economy. The consequences of financial

\footnotetext{
${ }^{1}$ For a critical assessment of this assumption, we refer the reader to the introduction of Bilbiie et al. (2007). According to their solution, we will use the terms "firm" and "good" interchangeably, as each firm in the model is specialised in the production of one type of good.
} 
shocks are particularly destabilizing: In contrast with real macroeconomic shocks, ${ }^{2}$ financial shocks have a cumulative effect on the two margins of activity. In particular, when looking at the time path of the effective share of entry on a quarter-on-quarter basis, we find that the contribution of financial shocks is slightly positive up to 2008, while it has a clear depressing impact on firm entry since 2009.

Third, the forecast error variance decomposition of the effective share of entry underlines the critical role played by financial factors in the period corresponding to the creation of new firms. In the very short run, new firms' creation is almost entirely explained by financial shocks (that explain around 50\% of the variance) and demand shocks. However in the longer run, the fluctuation of entries is mainly explained by supply shocks.

The rest of the paper is organized as follows. Section 2 presents the contribution of the paper to the literature on the extensive margin. Section 3 describes the role of the financial sector for the creation of new firms. Section 4 presents the rest of the model. Section 5 is devoted to the estimation of the model using Bayesian econometrics. Section 6 evaluates the consequences of financial frictions on the transmission of real and monetary shocks to the macroeconomic equilibrium. Section 7 studies the contribution of financial factors in the evolution of the extensive margin of activity. Section 8 evaluates the key role of the financial dividend policy and of the wage bill in advance requirement in shaping the dynamics of entry in the economy. Section 9 concludes.

\section{Contribution to the literature}

This paper studies the role of financial frictions on the intensive margin (changes in the production of existing goods) and extensive margin (changes in the number of varieties/firms) of US activity. Our analysis combines two growing branches of the macroeconomics literature in a Dynamic Stochastic General Equilibrium (DSGE) setting: models with endogenous firm entry and models accounting for the financial accelerator.

To our knowledge, the macroeconomic analysis of endogenous firms entry can be traced back to Peretto (1999), Ghironi and Melitz (2007) and Colciago and Etro (2010). By underlying the fact that activity moves at both the intensive and extensive margins, this literature has provided new insights on the way shocks are transmitted to the macroeconomic equilibrium. The path-breaking contribution of Bilbiie et al. (2007) has been particularly influential in providing a new standard for studying the transmission of real and monetary shocks in a tractable dynamic setting. These authors show how economic expansions induce higher entry rates and how the sluggish response in the number of producers (due to sunk entry costs and a time-to-build lag) generates a new and potentially important endogenous propagation mechanism for real business cycle models and monetary policy decisions in a sticky price environment. The key equation of their framework consists in a no-arbitrage condition that equalizes the market value of the prospective entrant to a sunk cost representing the cost of building a new activity. Their model also accounts

\footnotetext{
${ }^{2}$ Where investment in existing production lines and in new firms move in the opposite way, following the arbitrage of entrepreneurs regarding the allocation of financial resources between these two competing outcomes.
} 
for a time to build delay, as a new firm can only provide a new good to the consumer one period after its entry on the market. The entry period is devoted to the building of the new production line which incurs labour costs to the firm. This setting is particularly flexible for the analysis of a wide range of macroeconomic questions in both closed and open economies (see Etro (2014) for an up to date survey).

In the original model of Bilbiie et al. (2007), the opportunity of introducing new varieties for consumption is mainly affected by real factors. The financial environment plays a limited role in the building of new production lines, as investment in new productive units is financed by households through the accumulation of shares in the portfolio of firms. The stock-market price of this investment fluctuates endogenously in response to shocks independently of financial markets. This solution, that simplifies the financial side of the model, may be at odds with many real life situations, where entrepreneurs face a binding financial constraint to finance new projects. Following Etro (2014), credit market imperfections could be introduced to take into account the access to credit for business creation. As underlined by Casares and Poutineau (2013), surveys of current and potential entrepreneurs suggest that raising funds from the market and/or bank loans is one of the biggest hurdles to invest in a new business. Furthermore, as shown in different studies (Greenwood and Jovanovic (1990); Jayaratne and Strahan (1996); Levine (1997); Beck et al. (2000); Guiso et al. (2004)) cross-sectional differences in the ability of capital markets to select and finance the most promising entrepreneurs may lead to important differences in entrepreneurship and productivity growth across economies.

Financial intermediaries, such as banks, play a key role in the birth of new firms by relaxing the financial constraint of entrepreneurs over their net wealth. This role has already been underlined by a series of recent papers. La Croce and Rossi (2015) build a DSGE model with monopolistic competitive banks and endogenous firms entry. Focusing on the role of the banking sector in the interaction with firms' dynamics, they get higher volatilities of both real and financial variables than those implied by a fixed number of firms. In a companion paper, La Croce and Rossi (2014) consider a model with endogenous entry, flexible prices, monopolistic competitive banks and sticky interest rates, accounting for macroprudential policy rules. In both models, incumbent firms face a wage bill in advance constraint (a device that will be kept in our model) and financial frictions amplify the effect of shocks. A third example of this branch of the literature is Bergin et al. (2014). In their model, firms can finance entry costs through a combination of debt and equity, so that financial shocks directly impact the financing of firm entry. In their setting, they find that the entry of new firms limits the ability of incumbent firms to respond to negative financial shocks through endogenous capital restructuring. As an original result, they find that as the number of firms falls after an adverse financial shock. This provides an useful margin of macroeconomic adjustment that reduces the overall impact of the shock on aggregate output, as the remaining firms become financially stronger and better able to withstand a financial shock. Recently Rossi (2015) has underlined the key role of the banking sector in generating an additional shock transmission channel that tries to amplify the consequences of recessionary shocks on the extensive margin of activity in a model with endogenous entry and exit. ${ }^{3}$

\footnotetext{
${ }^{3}$ More particularly, she shows that the endogeneity of firms' exit generates an additional shock trans-
} 
In line with this growing literature, our paper provides an analysis of the interplay between the financial sector and the extensive margin of activity. However, we depart from these papers on three major strands:

First, we take into account the key role of the entrepreneur as the provider of funds for the creation of new varieties. This agent allocates its net wealth and loans obtained from the banking system between the financing of capital to firms already operating on the market and the financing of new firms creation, one period before the production of new goods. As in Poutineau and Vermandel (2015), we assume that entrepreneurs are optimistic, namely that they tend to overestimate the profitability of investment projects. This approach, that accounts for a key factor in the creation of new varieties, gives rise to a financial accelerator in line with Bernanke et al. (1999). As underlined by Etro (2014), this introduces a new mechanism of propagation and amplification of shocks that has nothing to do with capital accumulation, intertemporal substitution of labour and price rigidities.

Second, our model combines three types of rigidities related to prices, wages and lending rates. Regarding the later variable, we develop the role of the banking system that determines the interest rate of loans subscribed by entrepreneurs. This part of the model is in line with Bernanke et al. (1999), Gerali et al. (2010) and Christiano et al. (2014). We assume that banks collect deposits from households and lend to entrepreneurs. As in Gerali et al. (2010) and Darracq-Pariès et al. (2011), we take into account the imperfect pass-through of the policy rate to the bank lending rate. To get an homogenous representation of adjustment costs between agents, we suppose that banks are affected by an original Rotemberg (1982) technology when adjusting their lending rate. This nominal rigidity, that gives rise to an imperfect pass-through in the transmission of the policy rate to the lending rate, is deemed necessary to get a better fit of the model.

Third, in our setting we quantify the relative contribution of financial shocks to the fluctuations of the extensive margin of activity on US data between 1993Q1 and 2012Q3. These shocks have appeared to be an important source of macroeconomic fluctuations in recent times, as exemplified by the financial crisis of 2007-2009. Completing the original setting of Bilbiie et al. (2007) with a description of the financial sector closer to real life situations is helpful to understand how shocks related to the banking system (though the channel of lending interest rates) or to the stock exchange (through the value of the net wealth of entrepreneurs and the collateral required by the banking system to provide loans) affect the relative contribution of the extensive and intensive margins to output fluctuations of activity. In contrast to the existing literature presented above, we use Bayesian econometrics as in Smets and Wouters (2003, 2007) to assess the quantitative content of our analysis on US data. Our econometric approach is now standard to this class model and has previously been implemented by Lewis and Stevens (2015) in a monetary DSGE model with endogenous firm/product entry and a translog expenditure function. We complete this last paper by introducing financial frictions.

mission channel through the banking sector. Indeed, the indirect consequence of firms' endogenous default is that, every time firms' exit probability increases, banks optimally try to preserve their profits by increasing their interest rate on loans. Thus banks' mark-up becomes countercyclical, as it increases in face of recessionary shocks, while it decreases in response to expansionary shocks. 


\section{The Financial Sector}

The general structure of the model is summarized in Figure 1. The economy is populated by households, intermediate and final firms, entrepreneurs and a banking system. Households consume final goods and supply labour to firms. The intermediate sector produces intermediate goods that are combined by final firms to become final goods. Each firm is specialized in the production of a specific (either intermediate or final) good. The total number of final firms/goods is normalized to 1, while the total number of intermediate firms $/$ goods $^{4}$ is endogenously determined in the model to define the extensive margin of activity.

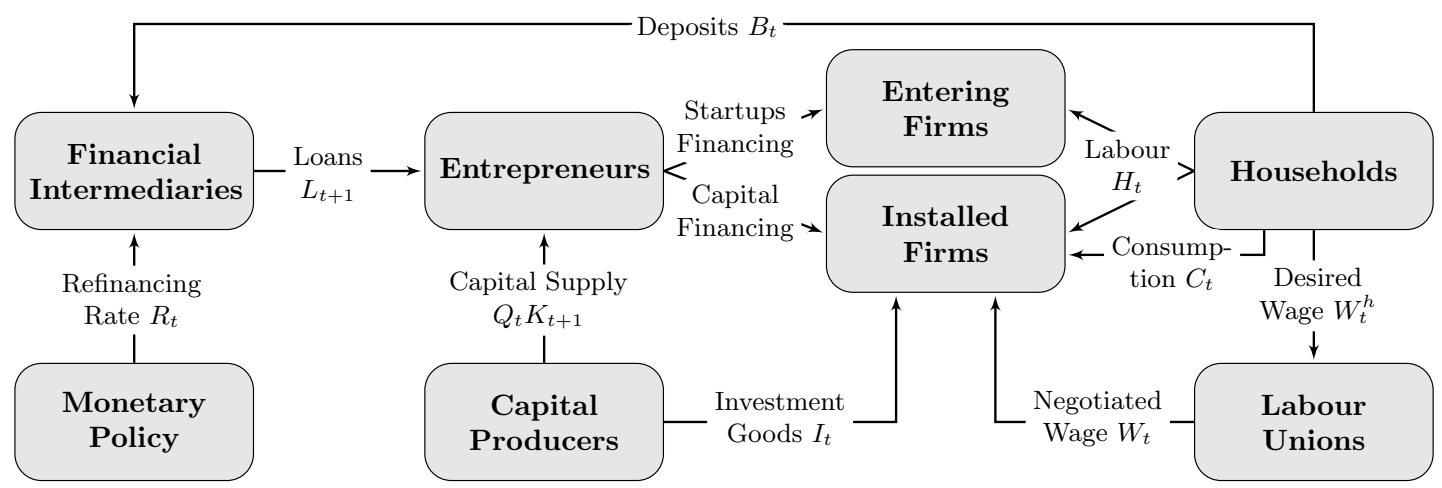

Figure 1: A new keynesian model with endogenous entry under financial frictions

To get a simple approach to the way financial decisions shape the dynamics of the model, we first single out the entrepreneur. This solution initially introduced by Bernanke et al. (1999) is helpful to get the intuition of the acceleration phenomenon in a DSGE setting with intensive and extensive margins. The rest of this section analyses the interactions between financial intermediaries, entrepreneurs and firms, according to Figure 2 while the rest of the model (summarized in Figure 1) will be presented in the next section.

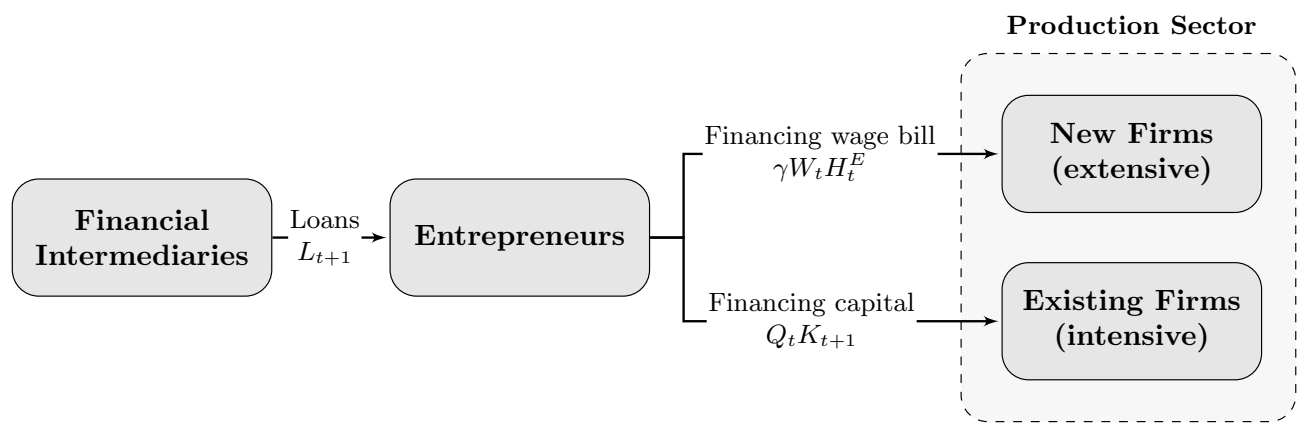

Figure 2: Implementing financial frictions in a model with endogenous entry

\footnotetext{
${ }^{4}$ Taking a broader view, it could be said that the creation of one new good corresponds to either one additional production line in an existing firm or the creation of a single new firm.
} 


\subsection{Entrepreneurs and the External Finance Premium}

Our economy is populated by entrepreneurs $e \in\left[0, n_{t}\right]$, where $n_{t}$ denotes the number of firms in the economy. The representative entrepreneur is a key agent for introducing financial frictions. ${ }^{5}$

This agent finances both the intensive margin (by renting capital to existing firms) and the extensive margin (by financing the wage bill for the creation of new firms). Entrepreneurs face a trade-off between intensive and extensive margins financing. On the one hand, the finance of new business in $t$ will automatically increase in $t+1$ both the stock of physical capital and entrepreneurs' profits. ${ }^{6}$ On the other hand, financing new business in $t$ rises entrepreneurs' leverage which in turn increases the cost of capital for existing firms and reduces the intensive margin. These two investment opportunities are financed by the entrepreneur's net wealth, denoted $N W_{e t+1}$, and by loans from the financial intermediary system denoted $L_{e t+1}^{d}$. The balance sheet of the representative entrepreneur is given by:

$$
\underbrace{L_{e t+1}^{d}}_{\text {loans }}+\underbrace{N W_{e t+1}}_{\text {net wealth }}=\underbrace{Q_{t} K_{e t+1}}_{\text {intensive production }}+\underbrace{\gamma W_{t} H_{e t}^{E}}_{\text {extensive production }} .
$$

where $\gamma$ denotes the fraction of inputs costs involved in the production process of new entrants, i.e. $W_{t} H_{e t}^{E}$ with $H_{e t}^{E}$ the hours worked required for starting new business at a wage $W_{t}$, while $K_{e t+1}$ denotes the total amount of physical capital involved in the intensive production by installed firms and $Q_{t}$ is the price of capital. These two investment opportunities are both financed by entrepreneurs through loans and net wealth.

The investment projects undertaken by the entrepreneur are risky and differ with respect to their individual returns. To model individual riskiness, we borrow from Bernanke et al. (1999) and assume that each project has an individual return equal to $\omega\left(1+R_{t}^{k}\right)$, i.e. that the aggregate return of investment projects in the economy $1+R_{t}^{k}$ is multiplied by a random value $\omega$. In this setting, we assume that the random value $\omega$ follows a Pareto distribution. Namely, $\omega \sim \mathcal{P}\left(\kappa, \omega_{\min }\right)$ where $\omega \in\left[\omega_{\min } ;+\infty[, \kappa>1\right.$ is the shape parameter and $\omega_{\min }>0$ is the minimum bound of $\omega$. The ex post profit of each project is, $\Pi_{e t}^{E}(\omega)=\omega\left(1+R_{t}^{k}\right) Q_{t-1} K_{e t}(\omega)-\left(1+R_{t-1}^{L}\right) L_{e t}^{d}(\omega)$ where $R_{t-1}^{L}$ is the lending rate decided by financial intermediaries. The critical value that distinguishes profitable from non-profitable projects is $\omega_{e t}^{C}$ such that $\Pi_{e t}^{E}\left(\omega_{e t}^{C}\right)=0$ :

$$
\omega_{e t}^{C}\left(1+R_{t}^{k}\right) Q_{t-1} K_{e t}\left(\omega_{e t}^{C}\right)=\left(1+R_{t-1}^{L}\right) L_{e t}^{d}\left(\omega_{e t}^{C}\right) .
$$

In order to acquire a loan, entrepreneurs have to engage in a financial contract before the realization of $\omega_{e t}^{C}{ }^{7}$ After engaging in the financial contract, entrepreneurs recognize

\footnotetext{
${ }^{5}$ The introduction of financial frictions is achieved through a financial accelerator $\grave{a}$ la Bernanke et al. (1999) reinterpreted in a banking perspective as in Poutineau and Vermandel (2015). We extend the model of Poutineau and Vermandel (2015) to account for the extensive margin of activity.

${ }^{6}$ The law of motion of firms in the economy is discussed in a following section (see equation Equation 20) and is standard with the canonical framework of Bilbiie et al. (2007).

${ }^{7}$ The endogenous threshold $\omega_{e t}^{C}$ is also referred as an idiosyncratic shock in the financial accelerator literature. The debt contract is conclude before the idiosyncratic shock is recognized which generates unexpected losses for the entrepreneurs.
} 
ex post the value of $\omega_{e t}^{C}$ which separates the default space $\left(\omega<\omega_{e t}^{C}\right)$ from the gainful space $\left(\omega \geq \omega_{e t}^{C}\right)$. Using the characteristics of the Pareto distribution $F(\omega)$, the distribution of stochastic investment projects $\omega$ has a positive support, is independently distributed (across entrepreneurs and time) with unitary mean $E[\omega]=1$, and density function $f(\omega)$. Investment projects above the cut-off value, $\omega>\omega_{e t}^{C}$, have positive profits $\Pi_{e t}^{E}(\omega) \geq 0$ which allows entrepreneurs to repay its loans to the bank. The share of profitable projects $1-$ $F(\omega)$ is computed as, $\eta=\operatorname{Pr}\left[\omega \geq \omega^{C}\right]=\int_{\omega^{C}}^{\infty} f(\omega) \mathrm{d} \omega=\left(\omega_{\min } / \omega^{C}\right)^{\kappa}$ while the conditional expectation of $\omega$ when entrepreneur's project is gainful is, $\eta \bar{\omega}=\int_{\omega C}^{\infty} \omega f(\omega) d \omega$ with $\bar{\omega}=$ $E\left[\omega \mid \omega \geq \omega^{C}\right]=\frac{\kappa}{\kappa-1} \omega^{C}$. Default occurs for projects below the cut-off value $\left(\omega<\omega_{e t}^{C}\right)$, in this situation it is too costly for the entrepreneur to pay back the contracted loan and prefers to default and obtain no gain from these projects. The expected profit of entrepreneur $e$ after aggregating all investment projects $\omega$ above the critical threshold $\left(\int_{\omega_{t+1}^{C}}^{\infty} \Pi_{e t+1}^{E}(\omega) \mathrm{d} \omega\right)$ requires that:

$$
d_{e t+1}^{E}=\left\{\begin{array}{c}
\bar{\omega}_{e t+1}\left(1+R_{t+1}^{k}\right) Q_{t} K_{e t+1}-\left(1+R_{t}^{L}\right) L_{e t+1}^{d} \text { with probability } \eta_{e t+1} \\
0 \text { with probability } 1-\eta_{e t+1}
\end{array}\right.
$$

where $\eta_{e t+1}\left(\bar{\omega}_{e t+1}\right)$ is the expected time-varying share (value) of gainful projects. As a main departure from both Bernanke et al. (1999) and the contract theory, we assume that entrepreneurs cannot screen the value of $\bar{\omega}_{e t+1}$ ex ante. Thus, $\omega_{e t}^{C}$ cannot be a control variable of the financial contract between borrowers and lenders. To introduce a financial accelerator mechanism, we follow Poutineau and Vermandel (2015) by assuming that entrepreneurs' forecasts regarding the aggregate profitability of a given project $\bar{\omega}_{\text {et }}$ are optimistic (i.e., biased upwards). As entrepreneurs hold distorted beliefs about their own ability and asset returns, the perceived ex ante value of profitable projects is defined by the isoleastic function:

$$
g\left(\bar{\omega}_{e t+1}\right)=\varphi\left(\bar{\omega}_{e t+1}\right)^{\frac{\varkappa}{(\varkappa-1)}}
$$

where $\varkappa$ is the elasticity of the external finance premium ${ }^{8}$ and $\varphi$ is a scale parameter. ${ }^{9}$ This function is such $g\left(\bar{\omega}_{i t}\right)>\bar{\omega}_{i t}$ for positive values of $\varkappa$. Ex-ante, the entrepreneur chooses to finance a total amount of capital $K_{\text {et+1 }}$ to maximize its expected profit given its biased appreciation of projects value. Namely, it maximizes:

$$
\max _{K_{e t+1}} \mathbb{E}_{t}\left\{\eta_{e t+1}\left[g\left(\bar{\omega}_{e t+1}\right)\left(1+R_{t+1}^{k}\right) Q_{t} K_{e t+1}-\left(1+R_{t}^{L}\right) L_{e t+1}^{d}\right]\right\}
$$

under the balance sheet constraint Equation 1. The first order condition which maximizes entrepreneur's profits reads as follows:

$$
\mathbb{E}_{t} \frac{\left(1+R_{t+1}^{k}\right)}{\left(1+R_{t}^{L}\right)}=\frac{1}{\mathbb{E}_{t} \varphi\left(\bar{\omega}_{e t+1}\right)^{\frac{\varkappa}{(\varkappa-1)}}}
$$

Using the characteristics of the Pareto distribution with $\bar{\omega}_{e t+1}=\kappa /(\kappa-1) \omega_{e t+1}^{C}$ and substituting the threshold $\omega_{e t+1}^{C}$ from Equation 2, the expected spread $S_{t}=\mathbb{E}_{t}\left(1+R_{t+1}^{k}\right) /\left(1+R_{t}^{L}\right)$

\footnotetext{
${ }^{8}$ The elasticity of the external finance premium expresses the degree of bias in estimating the expected rentability of entrepreneurs' projects such that $g\left(\bar{\omega}_{i t}\right)>\bar{\omega}_{i t}$ for $\varkappa>0$. Assuming an optimistic expectation bias, then $\mathbb{E}_{t}^{o p t} \bar{\omega}_{t+1}=\mathbb{E}_{t} \varphi\left(\bar{\omega}_{t+1}\right)^{\varkappa /(\varkappa-1)}$ where $\mathbb{E}_{t}^{o p t}$ is the expectation operator of optimistic entrepreneurs.

${ }^{9}$ This parameter is needed to make the steady state independent of $\varkappa$, such that $\varphi=\bar{\omega}^{1 /(1-\varkappa)}$.
} 
required by the representative entrepreneur $e$ to undertake the decision to finance physical capital firms is:

$$
S_{t}=\varphi^{\varkappa-1}\left[\frac{\kappa}{\kappa-1}\left(\frac{L_{e t+1}^{d}}{Q_{t} K_{e t+1}}\right)\right]^{\varkappa} .
$$

The size of the accelerator is determined by the elasticity of the external finance premium $\varkappa$. For $\varkappa>0$, the external finance premium is a positive function of the leverage ratio, $L_{e t+1}^{d} / Q_{t} K_{e t+1}$, so that an increase in net wealth $N W_{e t+1}$ induces a decrease in the external finance premium $S_{t}$. This phenomenon disappears if $\varkappa=0$. As the profitability of capital is a cost for the intermediate sector, a variation in the net wealth for $\varkappa>0$ has aggregate consequences on goods supply through the channel of capital markets. If the number of new firms increases, entrepreneurs borrow more to financial intermediaries which rises the external finance premium and the cost of capital for all installed firms. The relation obtained in Equation 7 can also be interpreted as a borrowing limit stating that the higher is the external finance premium the lower is the amount that can be borrowed.

The net wealth of the entrepreneur in the next period is equal to:

$$
N W_{e t+1}=(1-\delta)(1-\theta) d_{e t}^{E}+T_{e}^{E},
$$

where $d_{e t}^{E}$ is the one-period profit, $T_{e}^{E}$ is a constant net wealth transfer to new generation of entrepreneurs, ${ }^{10} \delta$ is the net wealth decay that is related to the exogenous exit rate shock of firms and $\theta$ represents the entrepreneur's dividends policy, i.e. the share of dividends distributed to shareholders (while the remaining fraction $1-\theta$ is reinvested in physical capital the next period). ${ }^{11}$ Combining Equation 3 and Equation 2, entrepreneurial dividends are given by:

$$
d_{e t}^{E}=\eta_{e t}\left(\bar{\omega}_{e t}-\omega_{e t}^{C}\right)\left(1+R_{t}^{k}\right) Q_{t-1} K_{e t} e^{\varepsilon_{t}^{N}} .
$$

where $\varepsilon_{t}^{N}$ is an exogenous collateral shock which affects both the net wealth accumulation process and the entrepreneurial dividends.

\subsection{Financial intermediaries}

Financial intermediaries provide funds to entrepreneurs. The representative financial intermediary $b \in[0,1]$ collects deposits from households and lends to firms. From the balance sheet of the financial intermediary, the loan supply is equal to the deposits as follows:

$$
L_{b t+1}=B_{b t+1}
$$

In this expression, $L_{b t}$ is the total level of loans supplied by financial intermediary $b, B_{b t}$ is the total level of deposit services offered by financial intermediary $b$ to households. The

\footnotetext{
${ }^{10}$ This assumption is taken from Faia (2007). Since entrepreneurs are also hit by a an exogenous exit shock $\delta$, this transfer to new generations of entrepreneur ensures new entrepreneurs have a non-zero amount of collateral at beginning of the next period. Transfers $T^{E}$ are determined endogenously in steady state via: $T^{E}=(1-\delta)(1-\theta) \bar{d}^{E}-\overline{N W}$.

${ }^{11}$ This dividend policy is deemed necessary to make the system response of the model consistent with the data. The macroeconomic implications of the entrepreneur dividend policy are further detailed in the paper.
} 
representative financial intermediary sets the rate of interest $R_{b t}^{L}$ and remunerates deposits by the interest rate $R_{t}$ controlled by the central bank.

Financial intermediaries finance heterogeneous investment projects conducted by entrepreneurs. Following Bernanke et al. (1999) and Poutineau and Vermandel (2015), if the borrower's project is gainful, the representative financial intermediary obtains $R_{b t}^{L} L_{b t+1}$ with a probability $\eta_{t+1}$, whereas if the entrepreneur's project is insolvent, the financial intermediary must pay auditing costs $\mu_{B}$ to recover the non-profitable investment project (i.e., $\left.\left(1-\mu^{B}\right) \underline{\omega}_{t+1} / \omega_{t+1}^{C} R_{b t}^{L} L_{b t+1}\right)^{12}$ with a probability $1-\eta_{t+1}$. In this setting, we assume that there is no discrimination between borrowers, so that the representative and risk-neutral financial intermediary serves all entrepreneurs without taking into account specificities regarding the viability of projects. Thereby the expected value of next period earnings is:

$$
\mathbb{E}_{t} \Pi_{b t+1}^{B}=\underbrace{\mathbb{E}_{t}\left\{\eta_{t+1}+\left(1-\mu_{B}\right)\left(1-\eta_{t+1}\right) \frac{\omega_{t+1}}{\omega_{t+1}^{C}}\right\}\left(1+R_{b t}^{L}\right) L_{b t+1}}_{\text {Revenues from loan supply activities }}-\underbrace{\left(1+R_{t}\right) B_{b t+1}}_{\text {deposit cost }} .
$$

As in Gerali et al. (2010), we take into account the imperfect pass-through of the policy rate on financial intermediary lending rate. We suppose that financial intermediaries set their interest rates on a staggered basis with some degree of nominal rigidity à la Rotemberg (1982). To introduce nominal rigidities, we assume financial intermediaries solve a two-stage problem. In a first stage, intermediaries evaluate the marginal cost of credit on perfectly competitive financial markets. The determination of interest rate on loans is as follows: the representative financial intermediary $b$ maximizes expected profit from Equation 11 with respect to $L_{b t+1}$ to obtain the expression of the marginal cost of producing new loans:

$$
1+M C_{b t}^{L}=\frac{\left(1+R_{t}\right)}{\mathbb{E}_{t}\left\{\eta_{t+1}+\left(1-\mu_{B}\right)\left(1-\eta_{t+1}\right) \frac{\omega_{t+1}}{\omega_{t+1}^{C}}\right\}} .
$$

In a second stage, financial intermediaries set their credit rate on a monopolistically competitive market with some degree of nominal rigidity. The Rotemberg adjustment cost function is given by:

$$
A C_{b t}^{L}=\frac{\kappa_{L}}{2}\left(\frac{R_{b t}^{L}}{R_{b t-1}^{L}}-1\right)^{2} R_{b t}^{L}
$$

where $\kappa_{L}$ denotes the cost for the representative bank of adjusting its interest rate. The representative financial intermediary sets the lending rate by solving:

$$
\max _{\left\{R_{b t}^{L}\right\}} \mathbb{E}_{t}\left\{\sum_{\tau=0}^{\infty} \beta^{\tau} \frac{\lambda_{t+\tau}^{c}}{\lambda_{t}^{c}}\left[R_{b t}^{L} L_{b t+1+\tau}-M C_{b t+\tau}^{L} L_{b t+1+\tau}-A C_{b t}^{L} L_{t+1}^{d}\right]\right\},
$$

where $\beta^{\tau} \lambda_{t+\tau}^{c} / \lambda_{t}^{c}$ is the household stochastic discount factor (see subsection 4.1 for further explanations). Given the imperfect competition on this market, financial intermediaries

\footnotetext{
${ }^{12}$ From the financial intermediary perspective, the expected value of investment projects in case of default is $\left.\underline{\omega}_{t+1}=E\left(\omega \mid \omega<\omega_{t+1}^{C}\right)\right)$. The total value of defaulting investment projects is thus, $\left(1-\eta_{t+1}\right) \underline{\omega}_{t+1} R_{t+1}^{k} Q_{t} K_{t+1}$. Recall that the cut-off investment project is $\underline{\omega}_{t+1} R_{t+1}^{k} Q_{t} K_{t+1}=R_{t}^{L} L_{t+1}$, then the total value of investment project the bank can size in case of default is $\left(1-\eta_{t+1}\right) \underline{\omega}_{t+1} / \omega_{t+1}^{C} R_{b t}^{L} L_{b t+1}$.
} 
provide differentiated loan types, sold to perfectly competitive loan packers who assemble them in a CES aggregator and sell the homogenous loan to entrepreneurs. Considering monopolistic competition as in Dixit and Stiglitz (1977): ${ }^{13}$

$$
L_{b t+1}=\left(R_{b t}^{L} / R_{t}^{L}\right)^{-\mu_{t}^{L} /\left(\mu_{t}^{L}-1\right)} L_{t+1}^{d}
$$

where $\mu_{t}^{L}$ denotes is a time-varying mark-up defined by $\mu_{t}^{L}=\exp \left(\varepsilon_{t}^{L}\right) \epsilon_{L} /\left(\epsilon_{L}-1\right)$. In this expression, $\epsilon_{L}$ denotes the degree of imperfect substitutability between different loan types and $\varepsilon_{t}^{L}$ is an exogenous $A R(1)$ mark-up shock to the credit rate equation. Finally anticipating symmetry between financial intermediaries, the interest rate that solves the optimization problem for the financial intermediary reads as follows:

$$
R_{t}^{L}=\mu_{t}^{L} M C_{b t}^{L}-\left(\mu_{t}^{L}-1\right) R_{t}^{L}\left(\frac{\partial A C_{b t}^{L}}{\partial R_{t}^{L}}+\beta \mathbb{E}_{t}\left\{\frac{\lambda_{t+1}^{c}}{\lambda_{t}^{c}} \frac{\partial A C_{b t+1}^{L}}{\partial R_{t}^{L}} \frac{L_{t+2}^{d}}{L_{b t+1}}\right\}\right)
$$

The real lending rate is thus defined by, $1+r_{t}^{L}=\left(1+R_{t}^{L}\right) / \mathbb{E}_{t} \pi_{t+1}^{C}$.

\section{The Rest of the Model}

This section is devoted to a formal presentation of the non-financial part of the model summarized in Figure 1. we successively provide details regarding decisions undertaken by households, labour-unions, the productive sector, the authorities and the general equilibrium conditions of the economy.

\subsection{Households}

There is a continuum of identical households who consume, save and work in intermediate firms. The total number of households is normalized to 1 . The the welfare index of the representative household $j \in[0,1]$ is defined as:

$$
\mathcal{W}_{j t}=\mathbb{E}_{t}\left\{\sum_{\tau=0}^{\infty} \beta^{\tau}\left[\frac{\left(C_{j t+\tau}-h C_{t-1+\tau}\right)^{1-\sigma_{C}}}{1-\sigma_{C}}-\chi \frac{H_{j t+\tau}^{1+\sigma_{H}}}{1+\sigma_{H}}\right]\right\}
$$

where variable $C_{j t}$ is the consumption index, $h \in[0,1]$ is a parameter that accounts for external consumption habits, $H_{j t}$ is labour effort, $\beta \in(0,1)$ is the discount factor and $\chi>0$ is a shift parameter in the utility function. The representative household allocates total consumption $C_{t}$ between a total number of $n_{t}$ goods, denoted $C_{i t}$, bundled by the final sector. The CES consumption bundle and the corresponding consumption price index are defined as, $C_{t}=\left(\int_{0}^{n_{t}} C_{i t} \frac{{ }^{\frac{\epsilon_{P}-1}{\epsilon_{P}}}}{\mathrm{c}} \mathrm{d} i\right)^{\frac{\epsilon_{P}}{\epsilon_{P}-1}}$ and $P_{t}^{C}=\left(\int_{0}^{n_{t}} P_{i t}{ }^{1-\epsilon_{P}} \mathrm{~d} i\right)^{\frac{1}{1-\epsilon_{P}}}$, where $\epsilon_{P}>1$ is the

\footnotetext{
${ }^{13}$ Loan packers are perfectly competitive and maximize profits, $R_{t}^{L} L_{t+1}^{d}-\int_{0}^{1} R_{b t}^{L} L_{b t+1} \mathrm{~d} b$, subject to the supply technology $L_{t+1}=\left(\int_{0}^{1}\left(L_{b t+1}(b)\right)^{1 / \mu_{t}^{L}} \mathrm{~d} b\right)^{\mu_{t}^{L}}$. The loan demand functions associated with this problem are, $L_{b t+1}=\left(R_{b t}^{L} / R_{t}^{L}\right)^{-\mu_{t}^{L} /\left(\mu_{t}^{L}-1\right)} L_{t+1}^{d}$, where $L_{t+1}^{d}$ is in equilibrium the aggregate demand for loans from entrepreneurs.
} 
elasticity of substitution between different varieties produced by firms. The consumption of a given type $i$ final goods is:

$$
C_{i t}=\left(P_{i t} / P_{t}^{C}\right)^{-\epsilon_{P}} C_{t}
$$

The budget constraint for the representative household can be expressed as:

$$
\begin{aligned}
w_{t}^{h} H_{j t}+e^{\varepsilon_{t-1}^{B}}(1 & \left.+R_{t-1}\right) \frac{B_{j t}}{P_{t}^{C}}+(1-\delta)\left(d_{j t}+v_{j t}+\theta d_{j t}^{E}\right)\left(x_{j t}+e^{\varepsilon_{t-1}^{E}}\left(1-A C_{j t-1}^{E}\right) n_{j t-1}^{E}\right) \\
& =C_{j t}+\frac{B_{j t+1}}{P_{t}^{C}}+v_{t} x_{j t+1}+n_{j t}^{E} f_{E} m c_{t}^{E}+T_{j t}-\Pi_{j t}^{W}-\Pi_{j t}^{B} .
\end{aligned}
$$

The income of the representative household is made of labour income (with desired real wage $\left.w_{t}^{h}\right){ }^{14}$ trade-unions $\Pi_{j t}^{W}$ and banks $\Pi_{j t}^{B}$ profits generated by the imperfect competition, and investment opportunities in three asset types: riskless nominal deposits $B_{j t}$, share holdings $x_{j t}$ and new firms $n_{j t}^{E}$. The expenditure side includes deposit services $B_{j t+1}$, consumption $C_{j t}$, shares purchase $x_{j t+1}$ at a market price $v_{t}$, investment in new startups $n_{j t}^{E} f_{E} m c_{t}^{E}$ (where $n_{j t}^{E}$ is the number of new entering firms, $f_{E}$ is a fixed entry cost and $m c_{t}^{E}$ is the marginal cost incurred by entering firms) and government taxes $T_{j t}$. Finally, following Smets and Wouters (2007) for physical capital, we add a stochastic shock $\varepsilon_{t}^{E}$ to the free entry condition which accounts for exogenous factors preventing a new firm from entering the market.

Concerning household's investment opportunities, $B_{j t}$ stands for the risk-free deposits subscribed in period $t-1$ and $R_{t-1}$ is the gross nominal rate of interest between period $t-1$ an period $t$. As in Smets and Wouters (2007), the profitability of deposits is affected by an exogenous $A R(1)$ premium shock $\varepsilon_{t}^{B}$ which aims at catching exogenous changes in households consumption expenditures. Second, households can also invest in startups (new firms) or existing firms. Previously financed startups $n_{j t-1}^{E}$ as well as shares purchased in the previous period pay a dividend $P_{t}^{C} d_{j t}$ from firms and $\theta d_{j t}^{E}$ from entrepreneurs and are worth $(1-\delta) P_{t}^{C} v_{t}$ at the end of period $t$. Parameter $\theta$ denotes the fraction of entrepreneurs profits distributed to shareholders, while the remaining fraction $1-\theta$ is reinvested in new investment projects. Each period all firms are affected by an exogenous exit shock $\delta$ which affects both entering and existing firms as in Bilbiie et al. (2007). Thus, the law of motion of firms in the economy is:

$$
n_{j t}=(1-\delta)\left(n_{j t-1}+e^{\varepsilon_{t-1}^{E}}\left(1-A C_{j t-1}^{E}\right) n_{j t-1}^{E}\right)
$$

The creation of new firms $n_{j t}^{E}$ is costly: households must invest an amount $f_{E} m c_{t}^{E}$ to create an endogenous number $n_{j t}^{E}$ of new firms, where $m c_{t}^{E}$ denotes the marginal cost of producing a new firm and $f_{E}$ is a sunk cost in the creation process of startups. ${ }^{15}$ The number of firms entering is also affected by an exogenous shock process $\varepsilon_{t}^{E}$ which aims at capturing exogenous factors allowing (preventing) a new firm to enter the market in case of positive (negative) realization. Following Lewis and Poilly (2012), we assume that not

\footnotetext{
${ }^{14}$ The households delegates the wage negotiation process to a representative trade union which negotiates the margin between the households desired wage $w_{t}^{h}$ and the real marginal product of labour of firms $w_{t}$. The trade union is detailed below in the next section.

${ }^{15}$ The creation of new firms/goods is detailed below in the production sector section.
} 
all startups are successful. A fraction $A C_{j t-1}^{E}$ of firms does not succeed in starting their business. The failure probability of startups is specified as:

$$
A C_{j t}^{E}=\frac{\chi_{E}}{2}\left(\frac{n_{j t}^{E}}{n_{j t-1}^{E}}-1\right)^{2}
$$

This function reflects congestion costs experienced by firms when many of them enter simultaneously the goods market. This cost aims at smoothing the dynamics of entry over the business cycle. ${ }^{16}$

Substituting the lagrange multipliers, we find the first order conditions that solve the household optimisation problem. First, the marginal utility of consumption is determined by: ${ }^{17}$

$$
\lambda_{t}^{c}=\left(C_{j t}-h C_{t-1}\right)^{-\sigma_{C}} .
$$

The Euler deposit condition on deposits, which determines the optimal consumption path, is:

$$
\beta \mathbb{E}_{t}\left\{\frac{\lambda_{t+1}^{c}}{\lambda_{t}^{c}}\right\} e^{\varepsilon_{t}^{B}} \frac{\left(1+R_{t}\right)}{\mathbb{E}_{t} \pi_{t+1}^{C}}=1 .
$$

The Euler equation on share, which drives the share value $v_{t}$, is determined by:

$$
v_{t}=(1-\delta) \beta \mathbb{E}_{t}\left\{\frac{\lambda_{t+1}^{c}}{\lambda_{t}^{c}}\left(d_{j t+1}+v_{j t+1}+\theta d_{j t+1}^{E}\right)\right\} .
$$

Put in a recursive form, the current value of shares is equal to the discounted sum of dividends as in the standard corporate finance theory. A positive value of $\theta$ affects the share price through the expected soundness of the financial system. Thus large negative financial shocks, such as the financial crisis episode, affect the expected dividends of entrepreneurs, which in turn drives down both the share price and the creation of new firms.

The first order condition determines the household labour supply:

$$
\lambda_{t}^{c} w_{t}^{h}=\chi H_{j t}^{\sigma_{H}} .
$$

Finally, the free entry equation is determined by the maximization of the household problem with respect to $n_{j t}^{E}$. Rearranged with the Euler share (Equation 24), the following expression for the free entry condition emerges:

$$
f_{E} m c_{t}^{E}=v_{t} \frac{\partial\left(1-A C_{j t}^{E}\right) n_{j t}^{E}}{\partial n_{j t}^{E}} e^{\varepsilon_{t}^{E}}+\beta \mathbb{E}_{t}\left\{v_{t+1} \frac{\partial\left(1-A C_{j t+1}^{E}\right)}{\partial n_{j t}^{E}} n_{j t+1}^{E} e^{\varepsilon_{t+1}^{E}}\right\} .
$$

As in Bilbiie et al. (2007), entry occurs until the firm value is equalized with the entry cost $f_{E} m c_{t}^{E}$, leading to the free entry condition. The free entry condition is also affected by the probability of failure $A C_{j t}^{E}$ because of congestion costs faced by the new firms when entering the market. Assuming a zero congestion cost function such that $\chi_{E}=0$, the free entry condition is the same as in Bilbiie et al. (2007).

\footnotetext{
${ }^{16}$ The convex functional form is directly borrowed from the investment cost function of Christiano et al. (2005).

${ }^{17}$ In equilibrium, the marginal utility of consumption equals the lagrange multiplier $\lambda_{t}^{c}$ associated to the household budget constraint.
} 


\subsection{Labour Unions}

In our setting, wages are sticky. To single out the determination and the dynamics of nominal wages, we assume that households delegate the task of negotiating their salary to labour unions. Formally, households provide differentiated types of labour, sold by labour unions to perfectly competitive labour packers who assemble them in a CES aggregator and sell the homogenous labour to intermediate firms. ${ }^{18}$ Each representative union is related to a household $j \in[0,1]$. We introduce Rotemberg (1982) adjustment costs into the wage setting equation with quadratic wage adjustment costs:

$$
A C_{j t}^{W}=\frac{\kappa_{W}}{2}\left(\frac{W_{j t}}{W_{j t-1}}-\left[\xi_{W} \pi_{t-1}^{C}+\left(1-\xi_{W}\right)\right]\right)^{2} \frac{W_{j t}}{P_{t}}
$$

where $\xi_{W}$ is a parameter measuring the rate of wage indexation between periods. ${ }^{19}$ Given this adjustment cost function, the optimization problem becomes dynamic. The representative union set the wage $W_{j t}$ by maximizing its expected margin between the firm's real labour marginal product and the household desired wage:

$$
\max _{\left\{W_{j t}\right\}} \mathbb{E}_{t}\left\{\sum_{\tau=0}^{\infty} \beta^{\tau} \frac{\lambda_{t+\tau}^{c}}{\lambda_{t}^{c}}\left(\frac{W_{j t+\tau}}{P_{t+\tau}} H_{j t+\tau}^{d}-\frac{W_{j t+\tau}^{h}}{P_{t+\tau}} H_{j t+\tau}^{d}-A C_{j t+\tau}^{W} H_{t+\tau}\right)\right\},
$$

subject to the downgrade sloping demand constraint from labour packers:

$$
H_{j t}=\left(W_{j t} / W_{t}\right)^{-\mu_{t}^{W} /\left(\mu_{t}^{W}-1\right)} H_{t}
$$

where $H_{j t}$ denotes the quantity of differentiated labour types $j$ used in the labour packer production function with a time-varying mark-up $\mu_{t}^{W}=\frac{\epsilon_{W}}{\epsilon_{W}-1} \exp \left(\varepsilon_{t}^{W}\right)$. Parameter $\epsilon_{W}$ denotes the degree of imperfect substitutability between different labour varieties supplied by households.

Anticipating symmetry over labour unions, the first order condition results in the following equation real wage equation:

$$
\frac{W_{t}}{P_{t}^{C}}=\mu_{t}^{W} \frac{W_{t}^{h}}{P_{t}^{C}}-\left(\mu_{t}^{W}-1\right) W_{t}\left[A C_{t}^{W \prime}+\beta \mathbb{E}_{t}\left\{\frac{\lambda_{t+1}^{c}}{\lambda_{t}^{c}} \frac{H_{t+1}}{H_{t}} A C_{t+1}^{W \prime}\right\}\right]
$$

\subsection{Production}

\subsubsection{The Intensive Margin}

This sector is populated by two groups of agents: intermediate firms and final firms. Intermediate firms produce differentiated goods $i$, choose labour and capital inputs, and set

\footnotetext{
${ }^{18}$ labour packers are perfectly competitive and maximize profits, $W_{t} H_{t}-\int_{0}^{1} W_{j t} H_{j t} \mathrm{~d} j$, subject to the supply technology $H_{t}=\left(\int_{0}^{1}\left(H_{j t} 1 / \mu_{t}^{W}\right) \mathrm{d} j\right)^{\mu_{t}^{W}}$. The labour demand functions associated with this problem are, $H_{j t}=\left(W_{j t} / W_{t}\right)^{-\mu_{t}^{W} /\left(\mu_{t}^{W}-1\right)} H_{t}$, where $H_{t}$ is in equilibrium the aggregate demand from firms.

${ }^{19}$ Empirically accounting for $\xi_{W}$ is necessary to fix the persistency of wage rigidity encountered in the data.
} 
prices according to the Rotemberg (1982) model. Final goods producers act as a consumption bundler by combining national intermediate goods to produce the homogenous final good. ${ }^{20}$

Each representative intermediate firm $i \in\left[0, n_{t}\right]$ is related to an entrepreneur $e$. Each firm has the following technology:

$$
Y_{i t}=e^{\varepsilon_{t}^{A}}\left(K_{i t+1}^{u}\right)^{\alpha}\left(H_{i t}^{d}\right)^{1-\alpha},
$$

where $Y_{i t}$ is the production function of the intermediate good that combines capital $K_{i t+1}^{u},{ }^{21}$ labour demand $H_{i t}^{d}$ and technology $e^{\varepsilon_{t}^{A}}$ (an $A R(1)$ productivity shock). Assuming capital requires one period to be settled and $u_{i t}$ denotes the capital utilization rate, the utilized capital involved in the production is reads:

$$
K_{i t+1}^{u}=u_{i t} K_{i t}
$$

Intermediate goods producers solve a two-stage problem. In the first stage, taken real input prices $w_{t}$ and $z_{t}$ as given, firms rent inputs $H_{i t}^{d}$ and $K_{i t+1}^{u}$ in a perfectly competitive factor markets in order to minimize costs subject to the production constraint. ${ }^{22}$ The first order condition leads to the real marginal cost expression:

$$
m c_{i t}=m c_{t}=\frac{1}{e^{\varepsilon_{t}^{A}}}\left(\frac{z_{t}}{\alpha}\right)^{\alpha}\left(\frac{w_{t}}{(1-\alpha)}\right)^{(1-\alpha)} .
$$

From the cost minimization problem, relative input demand must also satisfies,

$$
\alpha H_{i t}^{d} w_{t}=(1-\alpha) K_{i t+1}^{u} z_{t}
$$

In the second-stage, the intermediate firm operates monopolistically and sets the retail price according to a Rotemberg (1982) technology. Intermediate-good firms face adjustment costs on price changes, $A C_{i t}^{P}$ defined according to,

$$
A C_{i t}^{P}=\frac{\kappa_{P}}{2}\left(\frac{P_{i t}}{P_{i t-1}}-\left[\xi_{P} \pi_{t-1}+\left(1-\xi_{P}\right)\right]\right)^{2} \frac{P_{i t}}{P_{t}^{C}}
$$

where $\kappa_{P}$ is the cost of adjusting prices and $\xi_{P}$ is the coefficient that measures the rate of indexation to past rate of inflation of intermediate goods, $\pi_{t-1}=P_{t-1} / P_{t-2}$. Given this price adjustment cost specification, the problem of the representative firms becomes dynamic:

$$
\max _{\left\{P_{i t}\right\}} \mathbb{E}_{t}\left\{\sum_{\tau=0}^{\infty} \beta^{\tau} \frac{\lambda_{t+\tau}^{c}}{\lambda_{t}^{c}}\left(\frac{P_{i t+\tau}}{P_{t+\tau}^{C}}-m c_{i t+\tau}-A C_{i t+\tau}^{P}\right) Y_{i t+\tau}\right\} .
$$

\footnotetext{
${ }^{20}$ Final good producers are perfectly competitive and maximize profits, $P_{t}^{C} Y_{t}^{d}-\int_{0}^{n_{t}} P_{i t} Y_{i t} \mathrm{~d} i$, subject to the production function $Y_{t}^{d}=\left(\int_{0}^{n_{t}}\left(Y_{i t}{ }^{\left(\epsilon_{P}-1\right) / \epsilon_{P}}\right)\right)^{\epsilon_{P} /\left(\epsilon_{P}-1\right)}$. The intermediate demand functions associated with this problem are, $Y_{i t}=\left(P_{i t} / P_{t}^{C}\right)^{-\epsilon_{P}} Y_{t}^{d}$, where $Y_{t}^{d}$ is the aggregate demand.

${ }^{21}$ The capital utilization rate is determined below in the capital supplier's section.

${ }^{22}$ Each firm solves $\min _{K_{i t+1}^{u}, H_{i t}^{d}} w_{t} H_{i t}^{d}+z_{t} K_{i t+1}^{u}$ under the supply constraint.
} 
Firms operate in a monopolistically competitive market as in Dixit and Stiglitz (1977). Hence, the amount of firm-specific output, $Y_{i t}$, is demand-determined in response to its relative price $P_{i t} / P_{t}^{C}$ and to the aggregate demand for goods, $Y_{t}^{d}$, as follows,

$$
Y_{i t}=\left(\frac{P_{i t}}{P_{t}^{C}}\right)^{-\epsilon_{P}} Y_{t}^{d} .
$$

Here $\epsilon_{P}>1$ is the constant elasticity of substitution across goods. Anticipating symmetry and maximizing the expected stream of profits Equation 36 under the downward sloping constraint Equation 37, the first order conditions imply an optimal pricing policy such that the relative price $\rho_{i t}=P_{i t} / P_{t}^{C}$ is set as a mark-up over the marginal cost of production:

$$
\rho_{i t}=\mu_{i t} m c_{i t}
$$

where the endogenous mark-up $\mu_{i t}$ is defined as:

$$
\mu_{i t}=e^{\varepsilon_{t}^{P}} \frac{\epsilon_{P}}{\left(\epsilon_{P}-1\right)\left(1-\frac{P_{t}^{C}}{P_{i t}} A C_{i t}^{P}\right)+\kappa_{P} \Psi_{i t}} .
$$

Here $\varepsilon_{t}^{P}$ is an ad hoc mark-up shock process (i.e., a positive realization of $\varepsilon_{t}^{P}$ reduces the cost of adjusting prices, thus inducing a stronger inflation pressure) and $\Psi_{i t}$ is an auxiliary variable that depends on the Rotemberg (1982)-type cost of price adjustment. ${ }^{23}$

Finally, the profit of firms $i$ in real terms is given by:

$$
d_{i t}=\left(\rho_{i t}-m c_{i t}-A C_{i t}^{P}\right) Y_{i t}
$$

\subsubsection{The Extensive Margin}

Setting up new firms requires labour services. Each period, a continuum of new firms indexed $z \in\left[0, n_{t}^{E}\right]$ decides to enter the market. The production of new goods follows the same technology as Bilbiie et al. (2007):

$$
f_{E}=e^{\varepsilon_{t}^{A}} H_{z t}^{E}
$$

Considering perfect cross-sectoral factor mobility between intensive and extensive sectors, the cost of one unit of labour $W_{t}$ is the same across sectors. To introduce a financial friction in the production process of new firms, we incorporate a wage-bill in advance constraint. ${ }^{24}$ More precisely, entrepreneurs finance a fraction $\gamma \in[0,1]$ of the wage bill for the creation of new goods. As a result, the $z^{\text {th }}$ firm must borrow its wage bill, $W_{t} H_{z t}^{E}$, from the financial intermediary at the beginning of period $t$. Repayment occurs at the end of the period at the gross interest rate, $1+\gamma R_{t}^{L}$. The introduction of a wage bill in advance constraint is empirically motivated, for example Aghion et al. (2007) find that access to finance matters

\footnotetext{
${ }^{23}$ Specifically, $\Psi_{i t}=\left(\pi_{t}-\left[\xi_{P} \pi_{t-1}+\left(1-\xi_{P}\right)\right]\right) \pi_{t}-\beta \mathbb{E}_{t} \frac{\lambda_{t+1}^{c}}{\lambda_{t}^{c}}\left(\left(\pi_{t}-\left[\xi_{P} \pi_{t-1}+\left(1-\xi_{P}\right)\right]\right) \pi_{t+1} \frac{Y_{i t+1}}{Y_{i t}}\right)$.

${ }^{24}$ This assumption is close to the standard cash-in-advance constraint as in Lucas Jr and Stokey (1985). Such constraints were extended to wage bill or capital services bill, see for example Christiano et al. (2005).
} 
most for the entry of small firms and in sectors that are more dependent upon external finance.

The cost minimization problem leads to the real marginal cost expression for the production of a new good $z$ :

$$
m c_{z t}^{E}=m c_{t}^{E}=\frac{w_{t}\left(1+\gamma r_{t}^{L}\right)}{e^{\varepsilon_{t}^{A}}}
$$

For $\gamma>0$, the variation of the lending rate affects the decision to enter. In period of low lending rates, entrepreneurs have incentives to finance new goods' creation and generates positive extensive margins while in period of high financial distress characterized by important lending rate spreads, the financial constraint is too important to finance new firms, which negatively affects output.

The presence of financial frictions complicates the computation of the steady state. In our setting, financial frictions clearly affect the steady state number of firms $(\bar{n})$ that is given by:

$$
\bar{n}=\bar{H}\left[\frac{(1-(1-\delta) \beta) f_{E}(1-\alpha)\left(1+\gamma \bar{r}^{L}\right)}{(1-\delta) \beta\left((\bar{\mu}-1)+d^{K} \frac{\alpha}{\bar{z}}\right)}+f_{E} \frac{\delta}{(1-\delta)}\right]^{-1},
$$

where terms with a bar denotes the steady state value of the relevant variable and $d^{K}=$ $\theta \bar{\eta} \bar{\omega}^{C}(\kappa-1)^{-1}\left(1+\bar{r}^{k}\right)$. However, it should be noted that assuming there are no financial frictions such that, $\gamma=\theta=0$, the number of firms is the same as Bilbiie et al. (2007). This aspect is furthermore discussed in subsubsection B.2.2.

\subsection{Capital Suppliers}

Capital suppliers are homogeneous and distributed over a continuum normalized to one. The representative capital supplier $k \in[0,1]$ acts competitively to supply a quantity $K_{k t+1}$ of capital. Investment is costly, i.e. the capital supplier pays an adjustment cost $A C_{k t}^{I}$ on investment, such that $A C_{k t}^{I}=\frac{\chi_{I}}{2}\left(I_{k t} / I_{k t-1}-1\right)^{2}$. The capital stock of the representative capital supplier thus evolves according to:

$$
K_{k t+1}=e^{\varepsilon_{t}^{I}}\left(1-A C_{k t}^{I}\right) I_{k t}+(1-\delta) K_{k t}
$$

where $\varepsilon_{t}^{I}$ is an exogenous adjustment cost shock on investment which drives a wedge between the shadow value of capital $Q_{t}$ and the consumption price index $P_{t}^{C}$ (put differently, the real shadow value of capital $q_{t}=Q_{t} / P_{t}^{C}$ is non-constant for $\chi_{I} \neq 0$ ) The capital supplier produces the new capital stock $q_{t} K_{k t+1}$ by buying the depreciated capital $q_{t}(1-\delta) K_{k t}$ and investment goods $I_{k t}$. The representative capital supplier chooses $I_{k t}$ to maximize profits:

$$
\max _{\left\{I_{k t}\right\}} \mathbb{E}_{t}\left\{\sum_{\tau=0}^{\infty} \beta^{\tau} \frac{\lambda_{t+\tau}^{c}}{\lambda_{t}^{c}}\left[Q_{t} e^{\varepsilon_{t}^{I}}\left(1-A C_{k t}^{I}\right)-1\right] I_{k t}\right\},
$$

where $\beta^{\tau} \lambda_{t+\tau}^{c} / \lambda_{t}^{c}$ is the household stochastic discount factor presented in Equation 22 . The real price of capital renting thus solves:

$$
\varepsilon_{t}^{I} q_{t}=1+e^{\varepsilon_{t}^{I}} q_{t} \frac{\partial\left(I_{k t} A C_{k t}^{I}\right)}{\partial I_{k t}}+\beta \mathbb{E}_{t}\left\{\frac{\lambda_{t+1}^{c}}{\lambda_{t}^{c}} e^{\varepsilon_{t+1}^{I}} \pi_{t+1}^{C} q_{t+1} \frac{\partial\left(I_{k t+1} A C_{k t+1}^{I}\right)}{\partial I_{k t}}\right\}
$$


For capital utilization decisions, we follow Smets and Wouters (2007) assuming that the cost of adjusting the utilization rate $u_{t}$ of capital is given by:

$$
\Phi\left(u_{t}\right)=(1-\psi) / \psi \bar{Z}\left(\exp \left[\psi /(1-\psi)\left(u_{t}-1\right)\right]-1\right)
$$

where $\psi$ is the utilization cost elasticity, $\bar{Z}$ is the steady state marginal product of capital. Since in the steady state the utilization rate is normalized, $\bar{u}=1$, then $\Phi(u)=0$ and $\Phi^{\prime}(u)=\bar{Z}$. The optimal utilization rate of capital is determined by: ${ }^{25}$

$$
z_{t}=\bar{Z} e^{\psi /(1-\psi)\left(u_{t}-1\right)}
$$

where $z_{t}=Z_{t} / P_{t}^{C}$ is the real marginal product of capital. The profitability of one unit of capital is: ${ }^{26}$

$$
1+r_{t}^{k}=\frac{z_{t} u_{t}-\Phi\left(u_{t}\right)+(1-\delta) q_{t}}{q_{t-1}} .
$$

\subsection{Authorities}

The government finances public spending by charging a tax on households. The total amount of public spending, $P_{t} G_{t}$, is assumed to evolve according to an $A R(1)$ exogenous shock process $P_{t} \bar{G} \varepsilon_{t}^{G}$ and accounts for both government spending shocks and external shocks which alters the trade balance. The balance sheet of government is given by, $P_{t}^{C} \bar{G} \varepsilon_{t}^{G}=\int_{0}^{1} T_{j t} \mathrm{~d} j$.

The central bank reacts to fluctuations of price and activity imbalances. The general expression of the linear interest rule implemented by the central bank can be expressed as:

$$
R_{t}-\bar{R}=\rho\left(R_{t-1}-\bar{R}\right)+\left(1-\rho_{R}\right)\left[\phi_{\pi}\left(\pi_{t}-1\right)+\phi_{Y}\left(Y_{t}-\bar{Y}\right)\right]+\phi_{\Delta Y}\left(Y_{t}-Y_{t-1}\right)+\varepsilon_{t}^{R},
$$

where $\varepsilon_{t}^{R}$ is an exogenous $A R(1)$ monetary policy shock, $\phi^{\pi}, \phi_{Y}$ and $\phi_{\Delta Y}$ denote respectively the inflation, output gap and GDP growth gap parameters which aim at stabilizing the economy when deviating from its steady state.

\subsection{Shocks, Aggregation and Equilibrium conditions}

In this model, there are 10 structural shock processes defined by, $\varepsilon_{t}^{s}=\rho_{s} \varepsilon_{t-1}^{s}+\eta_{t}^{s}, s=$ $\{A, G, B, I, P, W, L, E, N, R\}$ and where $\rho_{s}$ are autoregressive roots of the exogenous variables, $\eta_{t}^{s}$, are standard errors that are mutually independent, serially uncorrelated and normally distributed with zero mean and variances $\sigma_{s}^{2}$. Following Smets and Wouters (2007), we augment the price and wage $A R(1)$ shock processes with an MA(1) term, denoted $u_{m}$, such that:

$$
\varepsilon_{t}^{m}=\rho_{m} \varepsilon_{t-1}^{m}+\eta_{t}^{m}-u_{m} \eta_{t-1}^{m}, \text { for } m=P, W .
$$

\footnotetext{
${ }^{25}$ The problem faced by capital suppliers when choosing the optimal utilization rate is : $\min _{u_{t}} P_{t}^{C} \Phi\left(u_{t}\right) K_{t}-Z_{t} u_{t} K_{t}$.

${ }^{26}$ The real unit of one unit of capital is micro-founded when the household takes the capital supply decisions. To improve the clarity of the model presentation, we decentralized the capital supply decisions to the capital supplier as in Bernanke et al. (1999).
} 
The $M A(1)$ term aims at catching high frequency fluctuations observed in price and wage time series. Finally we also follow Smets and Wouters (2007) assuming that the spending shock is affected by the productivity innovation in a proportion $\rho_{A G}$ :

$$
\varepsilon_{t}^{G}=\rho_{G} \varepsilon_{t-1}^{G}+\eta_{t}^{G}+\rho_{A G} \eta_{t}^{A} .
$$

After $(i)$ aggregating all agents and varieties in the economy, $(i i)$ imposing market clearing on all markets and (iii) substituting the relevant demand functions, the resource constraint for the economy, also defined as the GDP through the demand approach, reads as follows:

$$
Y_{t}^{d}=C_{t}+I_{t}+\bar{G} \varepsilon_{t}^{G}+\Phi\left(u_{t}\right) K_{t-1}+n_{t} A C_{t}^{P} Y_{t}+A C_{t}^{W} H_{t}+A C_{t}^{L} L_{t+1}
$$

Using the goods packer zero profit condition presented in subsection 4.3, the consumption price index is determined by, $P_{t}^{C}=\left(\int_{0}^{n_{t}} P_{i t}^{1-\epsilon_{P}} \mathrm{~d} i\right)^{1 /\left(1-\epsilon_{P}\right)}$. Rearranging this expression, the following expression for the relative price $\rho_{t}=P_{t} / P_{t}^{C}$ emerges:

$$
n_{t} \rho_{t}^{\left(1-\epsilon_{P}\right)}=1
$$

We can deduct the inflation rate $\pi_{t}^{C}$ from $\rho_{t}$ :

$$
\frac{\rho_{t}}{\rho_{t-1}}=\frac{\pi_{t}}{\pi_{t}^{C}}
$$

Aggregating total demand in Equation 37 for all varieties $n_{t}$ supplied by the economy leads to the clearing market condition for goods: ${ }^{27}$

$$
n_{t} Y_{t}=\rho_{t}^{-\epsilon_{P}} Y_{t}^{d}
$$

Concerning the production sector, we aggregate input factor capital services $\left(K_{t+1}^{u}=\right.$ $\left.\int_{0}^{n_{t}} K_{i t+1}^{u} \mathrm{~d} i\right)$ and labour demand of installed firms $\left(H_{t}^{d}=\int_{0}^{n_{t}} H_{i t}^{d} \mathrm{~d} i\right)$ and startups $\left(H_{t}^{E}=\right.$ $\left.\int_{0}^{n_{t}^{E}} H_{z t}^{E} \mathrm{~d} z\right)$. Aggregate supply in the economy follows:

$$
n_{t} Y_{t}=e^{\varepsilon_{t}^{A}}\left(K_{t+1}^{u}\right)^{\alpha}\left(H_{t}^{d}\right)^{1-\alpha} \text { and } n_{t}^{E} f_{E}=e^{\varepsilon_{t}^{A}} H_{t}^{E} .
$$

Turning to the labour market, the market clearing condition between households labour supply and demands from installed and new firms is:

$$
H_{t}=H_{t}^{d}+H_{t}^{E}
$$

Concerning the profit aggregation of Equation 40 and Equation 9, letting $K_{t+1}$ denote $\int_{0}^{n_{t}} K_{i t+1} \mathrm{~d} i$, the return from holding one fraction of shares $x_{j t}$ is:

$$
d_{t}=\left(\rho_{t}-m c_{t}-A C_{t}^{P}\right) Y_{t} \text { and } n_{t} d_{t}^{E}=\eta_{t}\left(\bar{\omega}_{t}-\omega_{t}^{C}\right)\left(1+R_{t}^{k}\right) Q_{t-1} K_{t} e^{\varepsilon_{t}^{N}} .
$$

Finally the general equilibrium condition is defined as a sequence of quantities $\left\{\mathcal{Q}_{t}\right\}_{t=0}^{\infty}$ and prices $\left\{\mathcal{P}_{t}\right\}_{t=0}^{\infty}$ such that for a given sequence of quantities $\left\{\mathcal{Q}_{t}\right\}_{t=0}^{\infty}$ and the realization of shocks $\left\{\mathcal{S}_{t}\right\}_{t=0}^{\infty}$, the sequence $\left\{\mathcal{P}_{t}\right\}_{t=0}^{\infty}$, guarantees the simultaneous equilibrium on all markets previously defined.

\footnotetext{
${ }^{27}$ The aggregation of all varieties reads: $\int_{0}^{n_{t}} Y_{i t}=n_{t} Y_{t}$.
} 


\section{Estimation}

Our empirical approach is a synthesis of the canonical estimation method of New Keynesian models of Smets and Wouters (2007), augmented with financial series as in Christiano et al. (2014) and combined with entry as in Lewis and Stevens (2015). We apply standard Bayesian estimation techniques as in Smets and Wouters (2003, 2007). In this section, we describe the data sources and transformations, before turning to our choice of priors and to the posterior distributions of the model parameters.

\subsection{Data}

The model is estimated with Bayesian methods on US quarterly data over the sample time period 1993Q1 to 2012Q3. Our sample is rather short because, as pointed out by Lewis and Stevens (2015), samples on business establishments are discontinued and short. We consider here the sample of Sadeghi (2008) as it spans over the 2007 financial turmoil, which is a key event in our analysis. The rest of the data are the same as Smets and Wouters (2007) (seven times series) and Christiano et al. (2014) (two financial time series) ${ }^{28}$ and are available on the Federal Reserve Bank of St. Louis website.

Concerning the transformation of series, the point is to map non-stationary data to a stationary model (namely, the GDP, consumption, investment and loan supply). Data which are known to have a trend or unit root are made stationary in two steps. First, we divide the sample by the population. Second, data are taken in logs and we use a first difference filtering to obtain growth rates. Real variables are deflated by GDP deflator price index. Following Chang et al. (2002), who underline the limited coverage of the nonfarm business sector compared to GDP, we multiply the index of average hours for the nonfarm business sector (all persons) by civilian employment.

Finally, we demean the data because we do not incorporate trends in our model. We are aware that the introduction of trends could affect our estimation results. However for tractability reasons, we have chosen to focus on short run macroeconomic fluctuations and to neglect long run effects involved by trends. Such an approach has also been chosen by Lewis and Stevens (2015) for a similar fit exercise on firms' entry.

The final dataset includes ten times series: real per capita growth rate of the GDP $\Delta \widehat{\mathcal{Y}}_{t}^{r l}$, consumption $\Delta \widehat{\mathcal{C}}_{t}^{r l}$, investment $\Delta \widehat{\mathcal{I}}_{t}^{r l}$, and loans $\Delta \widehat{\mathcal{L}}_{t}^{r l}$, as well as the quarterly federal funds rate $\mathcal{R}_{t}$ (divided by 4 to be on a quarterly basis), the quarterly corporate bond spread $\mathcal{S}_{t}$, the inflation rate $\Delta \hat{\mathcal{P}}_{t}$, the real inflation rate of wages $\Delta \widehat{\mathcal{W}}_{t}^{r}$, the per capita amount of hours worked in logs $\widehat{\mathcal{H}}_{t}^{l}$ and the effective share of entry $\widehat{\mathcal{N}}_{t}^{E}$. Figure 3 plots the transformed data. Letting $X_{t}^{r}, X_{t}^{l}$ and $\widehat{X}_{t}$ denote the real, the per capita and the log value of $X_{t}$ respectively, the vector of observable can be summarized by:

$$
y_{t}^{o b s}=\left[\begin{array}{llllllllll}
\Delta \widehat{\mathcal{Y}}_{t}^{r l} & \Delta \widehat{\mathcal{C}}_{t}^{r l} & \Delta \widehat{\mathcal{I}}_{t}^{r l} & \widehat{\mathcal{H}}_{t}^{l} & \Delta \hat{\mathcal{P}}_{t} & \Delta \widehat{\mathcal{W}}_{t}^{r} & \mathcal{R}_{t} / 4 & \mathcal{S}_{t} / 4 & \Delta \widehat{\mathcal{L}}_{t}^{r l} & \widehat{\mathcal{N}}_{t}^{E}
\end{array}\right]^{\prime},
$$

\footnotetext{
${ }^{28}$ More particularly for financial time series, we use commercial and industrial loans, and Moody's seasoned Baa corporate bond minus federal funds rate.
} 


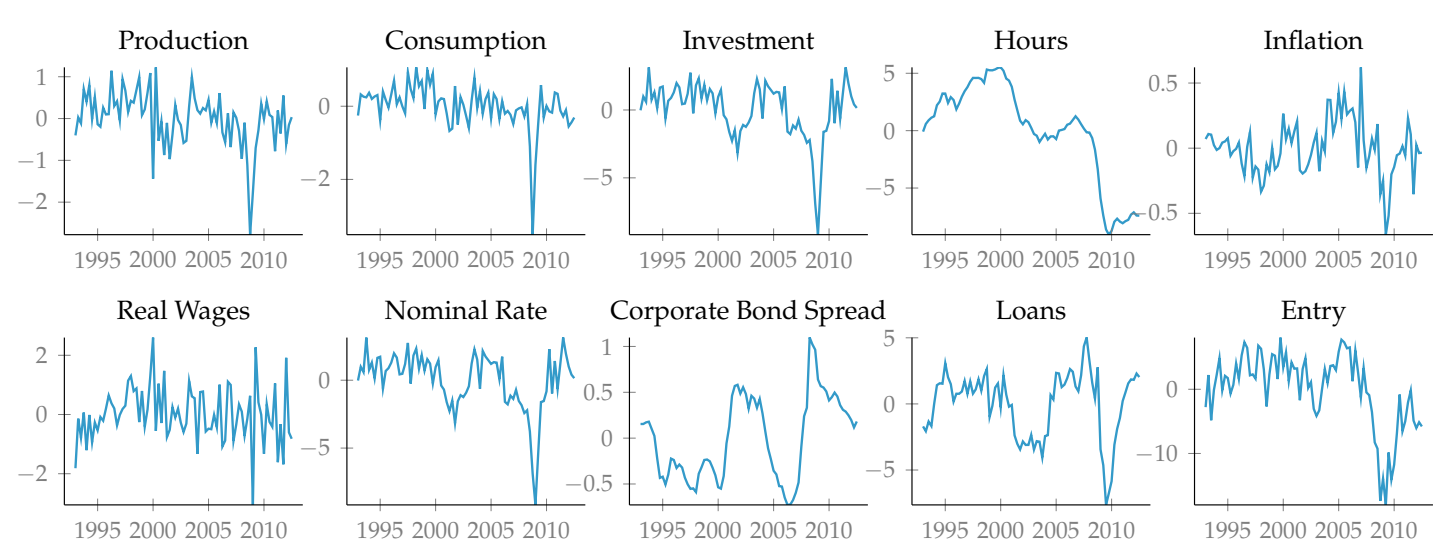

Figure 3: Observable variables used in the estimation

To make the model and the data consistent, we assume $\hat{x}_{t}=\log \left(X_{t} / \bar{X}\right)$ denotes the $\log$ deviation of $X_{t}$ from the steady state. Measurement equations read as follows:

$$
y_{t}=\left[\begin{array}{llllllllll}
\Delta \hat{y}_{t}^{d} & \Delta \hat{c}_{t} & \Delta \hat{\imath}_{t} & \hat{h}_{t} & \hat{\pi}_{t}^{C} & \Delta \hat{w}_{t} & R_{t} & \frac{1+R_{t}^{L}}{1+R_{t}} & \Delta \hat{l}_{t} & \frac{1}{1-\delta} \Delta \hat{n}_{t}
\end{array}\right]^{\prime}
$$

\subsection{Calibration and Prior Distribution of Parameters}

We fix a small number of parameters commonly used in the literature of real business cycle models which are either standard or weakly identified. The discount factor is $\beta=0.992$, which delivers an annual real riskless rate of $3.2 \%$. The depreciation rate of capital (or exit rate) is as Bilbiie et al. (2007), $\delta=0.025$. Following Smets and Wouters (2007), the elasticity of substitution between different labour varieties is set at $\epsilon_{W}=3$, implying a wage mark-up of $50 \%$ while for the analogous parameter for price is set at $\epsilon_{P}=3.8$ as in Bilbiie et al. (2007) and delivers a mark-up of 35\%. We calibrate the capital share $\alpha=0.40$ and the sunk cost $f_{E}=5$ in order to obtain a steady state investment-to-GDP ratio close to $16 \%$ while we follow Smets and Wouters (2007) by setting the spending-toGDP ratio to $18 \%, \bar{G} / \bar{Y}=0.18$. Households are assumed to spend $33 \%$ of their time working with $\bar{H}=1 / 3$. We calibrate the corporate bond spread as observed in the sample period, $\left(1+\bar{r}^{L}\right) /(1+\bar{r})=1+0.98 / 100$. Following Bernanke et al. (1999), the steady state entrepreneurs' default rate is set at $2.5 \%$ on an annual basis, $1-\bar{\eta}=2.5 / 400$, while the leverage ratio is set at $50 \%, \bar{L} / \bar{K}=0.50$. From the previous calibration, we can deduct the parameters of the Pareto distribution. Recall that following the Pareto distribution $\omega \sim \mathcal{P}\left(\kappa ; \omega_{\min }\right)$ where $\kappa$ is the shape parameter and $\omega_{\min }$ the minimum value of $\omega \in\left[\omega_{\min } ;+\infty\right)$. To obtain the value of $\omega_{\min }$ and $\kappa$, we solve the model's steady state assuming frictionless financial markets (i.e., $\bar{\omega}^{C}=\omega_{\min }$ and $\left.\bar{r}^{k}=\bar{r}^{L}\right)^{29}$. From Equation 2 in frictionless equilibrium, we find $\omega_{\min }=\bar{L} / \bar{K}$, while the first order condition of Equation 3 implies $\kappa=1 /\left(1-\omega_{\text {min }}\right)$. From this, it is straightforward to compute $\bar{r}^{k}$, and $\overline{m c}^{L}$ and $\bar{\omega}^{C}$. Our calibration delivers a steady state substitutability elasticity for loans close to 1.9,

\footnotetext{
${ }^{29}$ In our set-up, $\bar{\omega}^{C}$ denotes the endogenous risk in the economy. When $\omega^{C}$ hits the lower bound $\left(\bar{\omega}^{C}=\right.$ $\left.\omega_{\text {min }}\right)$, the economy is riskless implying $\bar{r}^{k}=\bar{r}^{L}$ so that when $\bar{\omega}^{C}>\omega_{\text {min }}$ there are financial frictions and defaulting entrepreneurs projects in steady state.
} 
this value is lower than the findings of Gerali et al. (2010). Finally for $\gamma$ the fraction of the wage bill financed in advance, no corresponding estimate is available with precision in the literature. Thus, we calibrate it so as to replicate some dynamic properties of entry with $\gamma=1$ (i.e. a negative response of entry after a credit rate increase).

Our priors are listed in Table 1 and Table 2. Overall, they are either consistent with the previous literature or relatively uninformative. For a majority of new Keynesian models' parameters, i.e. $\sigma_{C}, h, \xi_{P}, \xi_{W}, \chi_{I}, \psi, \phi_{\pi}, \phi_{Y}, \phi_{\Delta Y}, \rho, u_{P}, u_{W}, \rho_{A G}$ and shocks processes parameters $\rho_{s}$ and standard deviations of innovations $\sigma_{s}$ for $s=\{A, G, B, I, P, W, L, E, N, R\}$, we use the prior distributions chosen by Smets and Wouters (2003, 2007). We depart from the canonical priors' specification of Smets and Wouters on two aspects to be empirically relevant with the data. First, the labour disutility parameter $\sigma_{H}$ should remain below 1 as in the first generation of RBC models in order to dampen the response of hours and entry (especially after a monetary shock). The second aspect also aims at dampening hours worked and entry responses, assuming that nominal rigidities for wages are largely higher than for prices. This assumption is empirically motivated as exemplified for example by the estimated results of Smets and Wouters (2007) for the US economy. For the curvature of labour utility, we impose a beta distribution with mean 0.50 and standard deviation 0.10. The Rotemberg price and wage adjustment cost parameters $\kappa_{P}$ and $\kappa_{W}$ are assumed to be 50 and 70 respectively with a common standard deviation of 5 . These values are consistent with both Gerali et al. (2010) and Lewis and Stevens (2015). Our priors for the Rotemberg adjustment cost for credit rates is close to Gerali et al. (2010) with a mean of 10 and a standard deviation of 2.5. We set the prior for the elasticity of the external finance premium $\varkappa$ to a normal distribution with prior mean equal to 0.05 and standard deviation 0.02 consistent with the benchmark calibration of Bernanke et al. (1999). For the auditing cost $\mu_{B}$, our prior is inspired by Christiano et al. (2014) with a mean of 0.25 and a standard deviation of 0.05 . For the entrepreneurial dividends policy parameter $\theta \times 100$, to our knowledge there is no micro-evidence on the value of this parameter, we impose a fairly loose prior with a diffuse normal distribution, mean and standard are set at 5 and 0.75 respectively. Finally, the adjustment cost on entry $\chi_{E}$ has a prior mean of 0.4 and a standard deviation of 0.10, which is below the priors of Casares and Poutineau (2014) and Lewis and Stevens (2015), but this assumption is deemed necessary to obtain a response of entry consistent with the data. 

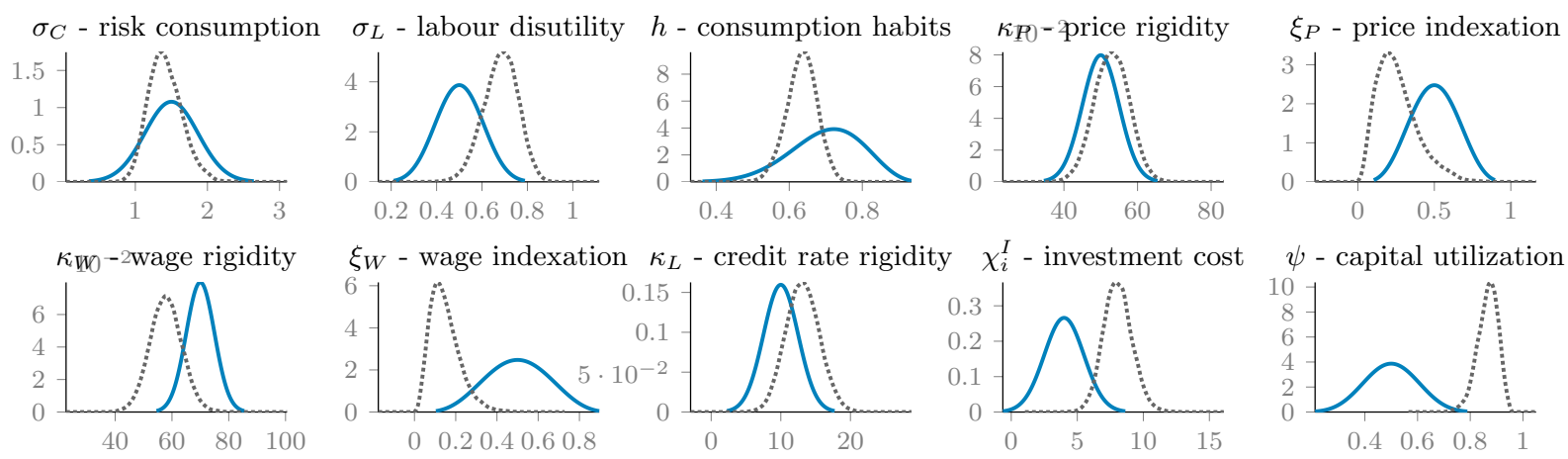

$\phi^{\pi}$ - taylor inflation
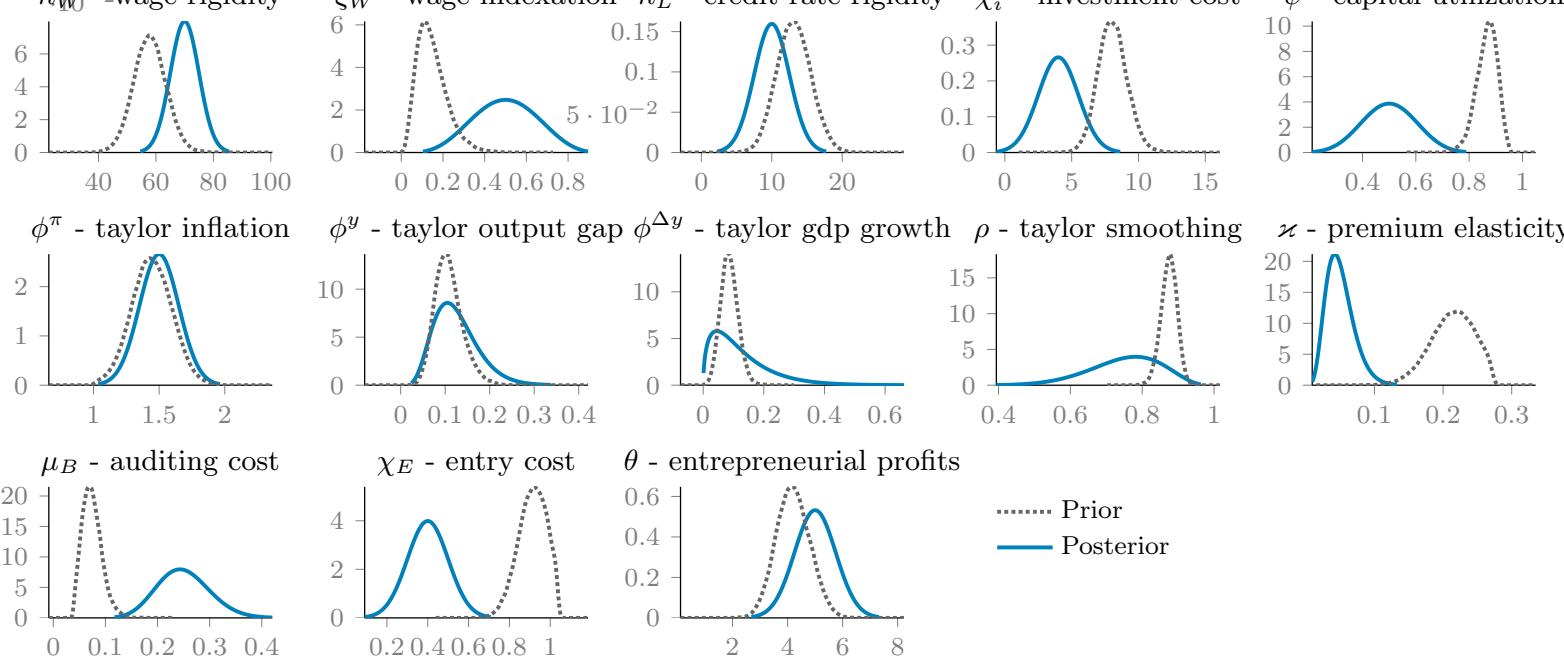

Figure 4: Prior and posterior distributions of structural parameters.

\subsection{Posterior Estimates}

The methodology is standard to the Bayesian estimations of DSGE models. ${ }^{30}$ Figure 4 reports the prior and posterior marginal densities of the parameters of the model, excluding the standard deviation and $A R$ and $M A$ terms of shocks. According to Figure 4, the data were relatively informative except for two parameters for which posterior distributions stay very close to the chosen priors. These parameters are the inflation weight in the Taylor rule $\phi_{\pi}$ and the price adjustment cost $\kappa_{P}$. The inflation weight is commonly not well identified as it strongly interacts with the smoothing parameter $\rho$ (see for example An and Schorfheide (2007)). Concerning $\kappa_{P}$, his weak identification is caused by the small size of the sample period considered in the estimation exercise. Increasing the numbers of periods in the sample would solve the issue, but we are constrained by the availability of entry data.

Our results are largely in line with the estimates of Smets and Wouters (2007). Comparing our results for nominal rigidities with those obtained by Lewis and Stevens (2015), the price adjustment cost estimate is slightly lower, while it is similar for the wage. Our

\footnotetext{
${ }^{30}$ The number of shocks and observable variables are the same to avoid stochastic singularity issue. The posterior distribution combines the likelihood function with prior information. To calculate the posterior distribution to evaluate the marginal likelihood of the model, the Metropolis-Hastings algorithm is employed. To do this, a sample of 120,000 draws was generated on 4 different chains, neglecting the first 20,000. The scale factor was set in order to deliver acceptance rates of between 20 and 30 percent (here roughly 24\%). Convergence was assessed by means of the multivariate convergence statistics taken from Brooks and Gelman (1998). The estimation was performed using Dynare version 4.4.3 developed by Adjemian et al. (2014).
} 


\begin{tabular}{|c|c|c|c|c|c|c|}
\hline \multirow{3}{*}{ Structural PARAMETERS } & & \multicolumn{3}{|c|}{ Prior distributions } & \multirow{2}{*}{\multicolumn{2}{|c|}{$\begin{array}{c}\text { Posterior distribution } \\
\text { Mean [5\%:95\%] }\end{array}$}} \\
\hline & \multirow[b]{3}{*}{$\sigma_{C}$} & \multirow{3}{*}{$\begin{array}{l}\text { Shape } \\
\mathcal{N}\end{array}$} & \multirow{3}{*}{$\begin{array}{c}\text { Mean } \\
1.5\end{array}$} & \multirow{3}{*}{$\begin{array}{l}\text { Std. } \\
0.37\end{array}$} & & \\
\hline & & & & & & \\
\hline Consumption aversion & & & & & 1.41 & [1.03:1.79] \\
\hline Labour disutility & $\sigma_{L}$ & $\mathcal{G}$ & 0.5 & 0.1 & 0.68 & {$[0.56: 0.8]$} \\
\hline Consumption inertia & $h$ & $\mathcal{B}$ & 0.7 & 0.1 & 0.63 & {$[0.56: 0.7]$} \\
\hline Price rigidity & $\kappa_{P}$ & $\mathcal{N}$ & 50 & 5 & 52.9 & [45.2:60.56] \\
\hline Price indexation & $\xi_{P}$ & $\mathcal{B}$ & 0.5 & 0.15 & 0.26 & [0.05:0.45] \\
\hline Wage rigidity & $\kappa_{W}$ & $\mathcal{N}$ & 70 & 5 & 57.82 & {$[48.35: 66.79]$} \\
\hline Wage indexation & $\xi_{W}$ & $\mathcal{B}$ & 0.5 & 0.15 & 0.15 & [0.04:0.25] \\
\hline Credit rate rigidity & $\kappa_{L}$ & $\mathcal{N}$ & 10 & 2.5 & 13.11 & [9.19:17.09] \\
\hline Investment cost & $\chi_{I}$ & $\mathcal{N}$ & 4 & 1.5 & 8.05 & {$[6.27: 9.81]$} \\
\hline Capital utilization & $\psi$ & $\mathcal{B}$ & 0.5 & 0.1 & 0.87 & [0.8:0.93] \\
\hline MPR inflation & $\phi_{\pi}$ & $\mathcal{N}$ & 1.5 & 0.15 & 1.44 & [1.19:1.69] \\
\hline MPR output gap & $\phi_{Y}$ & $\mathcal{G}$ & 0.125 & 0.05 & 0.11 & {$[0.06: 0.16]$} \\
\hline MPR output growth & $\phi_{\Delta Y}$ & $\mathcal{G}$ & 0.125 & 0.1 & 0.09 & [0.04:0.13] \\
\hline MPR smoothing & $\rho$ & $\mathcal{B}$ & 0.75 & 0.1 & 0.87 & [0.84:0.91] \\
\hline Finance Premia & $\varkappa$ & $\mathcal{B}$ & 0.05 & 0.02 & 0.21 & {$[0.17: 0.27]$} \\
\hline Auditing cost & $\mu_{B}$ & $\mathcal{B}$ & 0.25 & 0.05 & 0.07 & {$[0.04: 0.1]$} \\
\hline Entrepreneurial dividends & $\theta \times 100$ & $\mathcal{N}$ & 5 & 0.75 & 4.19 & [3.22:5.21] \\
\hline Entry adjustment cost & $\chi_{E}$ & $\mathcal{N}$ & 0.4 & 0.1 & 0.91 & {$[0.82: 1.04]$} \\
\hline Margin & al likelihs & & & & & 1128.15 \\
\hline
\end{tabular}

Table 1: Prior and Posterior distributions of structural parameters

estimation of the external finance premium $\varkappa$ is twice higher than De Graeve (2008), and even more compared to Poutineau and Vermandel (2015). This result suggests the financial amplification mechanism is more important with entry. Our estimates of the credit rate adjustment $\operatorname{cost} \kappa_{L}$ is slightly higher than Gerali et al. (2010) for the Euro area. Finally, the auditing cost estimation is in line with the calibration of Bernanke et al. (1999), but is clearly below the estimate of Christiano et al. (2014).

\section{The Consequence of Financial Frictions on the Prop- agation of Non Financial Shocks}

To evaluate how financial frictions affect the dynamics of the model, we report the simulated responses of the main macroeconomic and financial variables following standard non-financial shocks generally encountered in the literature related to the extensive margin of activity: a positive shock to productivity, public spending, cost-push innovations and on the monetary policy interest rate. In these experiments we contrast the reaction of the model without (in dotted lines) and with (in plain lines) financial frictions. The description of the diffusion of financial shocks is left to the next section. 


\begin{tabular}{|c|c|c|c|c|c|c|}
\hline \multirow{3}{*}{$\operatorname{AR}(1), \operatorname{MA}(1)$ TERM } & & \multicolumn{3}{|c|}{ Prior distributions } & \multirow{2}{*}{\multicolumn{2}{|c|}{$\begin{array}{l}\text { Posterior distribution } \\
\text { Mean [5\%:95\%] }\end{array}$}} \\
\hline & & \multirow[t]{2}{*}{ Shape } & \multirow[t]{2}{*}{ Mean } & \multirow[t]{2}{*}{ Std. } & & \\
\hline & & & & & & \\
\hline AR - Productivity & $\rho_{A}$ & $\mathcal{B}$ & 0.5 & 0.2 & 0.99 & [0.98:1.00] \\
\hline AR - Spending & $\rho_{G}$ & $\mathcal{B}$ & 0.5 & 0.2 & 0.96 & [0.94:0.99] \\
\hline AR - Premium & $\rho_{B}$ & $\mathcal{B}$ & 0.5 & 0.2 & 0.87 & [0.76:0.97] \\
\hline AR - Investment & $\rho_{I}$ & $\mathcal{B}$ & 0.5 & 0.2 & 0.99 & [0.99:1.00] \\
\hline AR - Price cost-push & $\rho_{P}$ & $\mathcal{B}$ & 0.5 & 0.2 & 0.63 & {$[0.37: 0.87]$} \\
\hline AR - Wage cost-push & $\rho_{W}$ & $\mathcal{B}$ & 0.5 & 0.2 & 0.99 & [0.99:1.00] \\
\hline AR - Rate cost-push & $\rho_{L}$ & $\mathcal{B}$ & 0.5 & 0.2 & 0.84 & [0.79:0.90] \\
\hline AR - Entry shock & $\rho_{E}$ & $\mathcal{B}$ & 0.5 & 0.2 & 0.43 & [0.29:0.57] \\
\hline AR - Collateral & $\rho_{N}$ & $\mathcal{B}$ & 0.5 & 0.2 & 0.95 & [0.92:0.98] \\
\hline AR - Monetary policy & $\rho_{R}$ & $\mathcal{B}$ & 0.5 & 0.2 & 0.48 & [0.36:0.59] \\
\hline Productivity-Spending & $\rho_{A G}$ & $\mathcal{B}$ & 0.5 & 0.2 & 0.41 & [0.13:0.67] \\
\hline MA - price & $u_{P}$ & $\mathcal{B}$ & 0.5 & 0.2 & 0.35 & [0.13:0.56] \\
\hline MA - wage & $u_{W}$ & $\mathcal{B}$ & 0.5 & 0.2 & 0.88 & [0.84:0.92] \\
\hline INNOVATIONS & & & & & & \\
\hline Productivity & $\eta_{t}^{A}$ & $\mathcal{I} \mathcal{G}$ & 0.1 & 2 & 0.96 & [0.82:1.09] \\
\hline Spending & $\eta_{t}^{G}$ & $\mathcal{I G}$ & 0.1 & 2 & 2.32 & [2.01:2.64] \\
\hline Premium & $\eta_{t}^{B}$ & $\mathcal{I} \mathcal{G}$ & 0.1 & 2 & 0.40 & [0.23:0.58] \\
\hline Investment & $\eta_{t}^{I}$ & $\mathcal{I G}$ & 0.1 & 2 & 3.96 & [3.38:4.55] \\
\hline Price cost-push & $\eta_{t}^{P}$ & $\mathcal{I G}$ & 0.1 & 2 & 0.05 & [0.04:0.07] \\
\hline Wage cost-push & $\eta_{t}^{W}$ & $\mathcal{I} \mathcal{G}$ & 0.1 & 2 & 0.27 & [0.21:0.32] \\
\hline Rate cost-push & $\eta_{t}^{L}$ & $\mathcal{I} \mathcal{G}$ & 0.1 & 2 & 0.18 & [0.15:0.21] \\
\hline Entry shock & $\eta_{t}^{E}$ & $\mathcal{I G}$ & 0.1 & 2 & 2.00 & [1.68:2.30] \\
\hline Collateral & $\eta_{t}^{N}$ & $\mathcal{I G}$ & 0.1 & 2 & 0.64 & [0.48:0.78] \\
\hline Monetary policy & $\eta_{t}^{R}$ & $\mathcal{I G}$ & 0.1 & 2 & 0.09 & {$[0.08: 0.10]$} \\
\hline Marg & al like & ihood & & & & 128.15 \\
\hline
\end{tabular}

Table 2: Prior and Posterior distributions of shock processes

\subsection{Productivity shock}

Figure 5 depicts the impulse responses of an increase in productivity on the main variables of the model. As standardly documented in the literature, this shock lowers firms' real marginal costs (Equation 33). As prices are sticky and do not fall according to the same amount, this rises markups and increases profits and firms value (Equation 40). The fall in entry costs (measured in terms of the marginal cost of production) and the rise in firms value lead to more entry on the goods market. In turn, the greater profitability of firms leads investors to invest more. As time goes, prices decrease which leads to an increase in consumption. The combination of the dynamics of the extensive margin and intensive margin of activity imply a higher increase in GDP.

As documented by the plain line, the financial constraints - related to the need for entrepreneurs to get loans from the banking system in order to finance investment in existing firms and the creation of new goods' varieties - clearly affects the dynamics of the macroeconomic variables. Moreover, financial frictions have a dampening effect on 
the creation of new varieties, as entrepreneurs need to get loans to finance salaries during the building of the new production lines to meet its financial constraint (Equation 1). Furthermore, as new firms require loans, this increases the cost of firms' creation which limits the increase in the market value of firms. However, this contractionary effect is not significant during the initial five periods (as one should notice both lines are the same).

As previously underlined in the presentation of the framework, entrepreneurs have to make an arbitrage between the creation of new varieties and financing investment in existing firms. Maintaining the flow of goods creation during the first periods after the productivity shock leads entrepreneurs to divert financial resources from investment, and, as a consequence, the positive shock on productivity implies a - seemingly counter-intuitive - decrease in investment. This dynamics of investment has a negative impact on the intensive margin of activity. Combining the new dynamics of the two margins of activity, we observe a lower increase in GDP. In the meanwhile, the drop in investment and the lower increase of consumption after 5 periods lead to a decrease in goods demand higher than in goods supply, which reinforces the deflationary effect of the productivity shock.

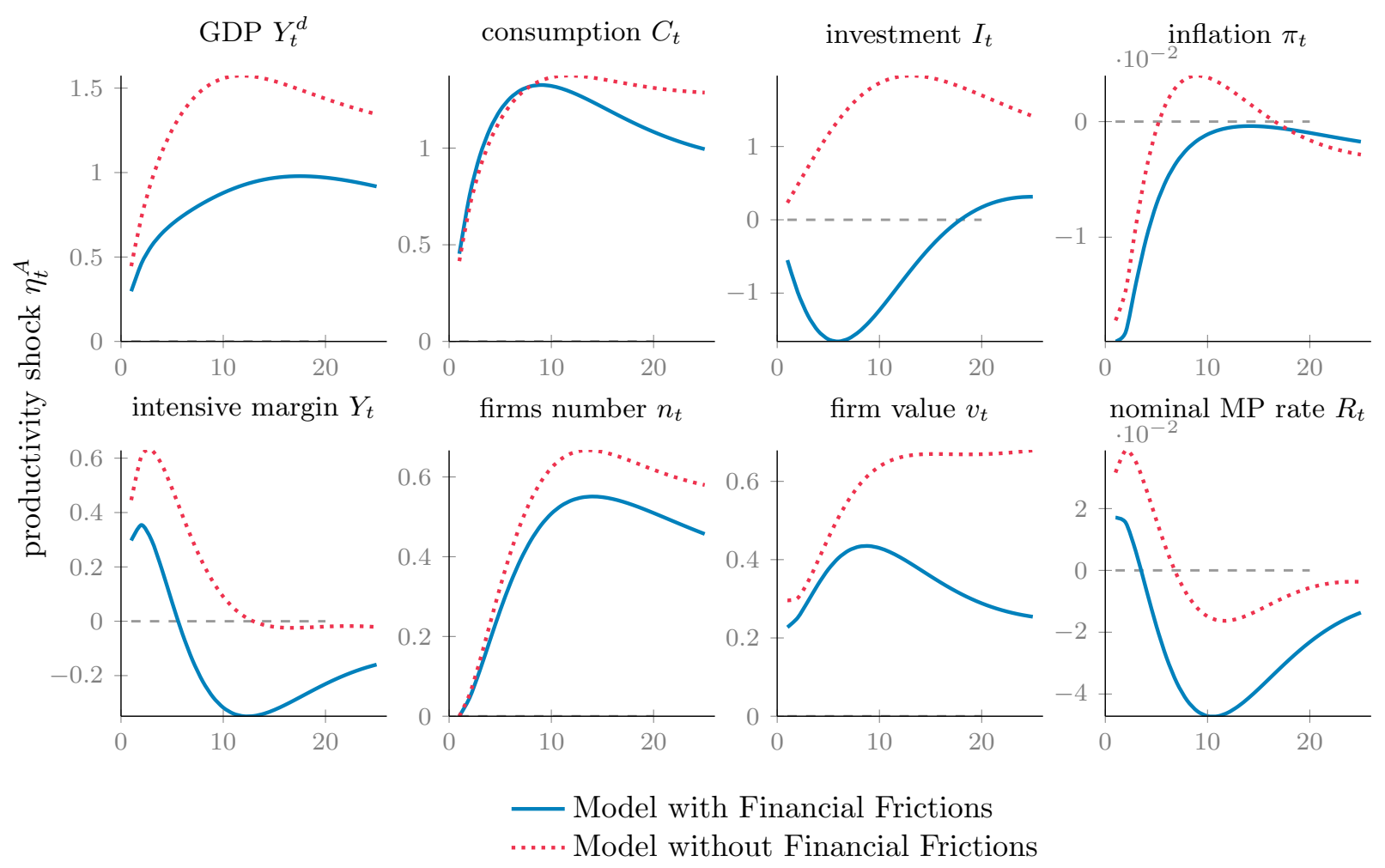

Figure 5: System response to an estimated productivity shock $\eta_{t}^{A}$ measured in percentage deviations from steady state with financial frictions (plain blue) and without (dashed red).

Note: These IRFs are obtained classically by calibrating the model at the posterior mean as reported in Table 1 and Table 2. 


\subsection{Spending shock}

Figure 6 depicts the impulse responses of an increase in government spending. As observed, this shock increases the inflation rate in the economy, which erodes the real value of firms dividends (Equation 40) and, as a consequence, the real market value of firms and firm entry decrease. The increase in the inflation rate requires an increase in the policy rate through the Taylor rule (Equation 49) . This in turn depresses both investment and consumption. Thus, the increase in activity is mainly explained by the evolution of the intensive margin with a marginal negative contribution of the extensive margin.

As reported with the plain line, financial constraints accelerate the drop in the extensive margin of activity. Indeed, as the creation of new firms require the availability of loans to finance the creation of new production lines, the increase in the lending interest rate (Equation 16) reinforces the drop in the creation of new varieties. The value of firms initially decreases more with than without financial frictions. As a consequence, entrepreneurs tend to favour more investment in existing firms (which now becomes positive). This in turn, helps to maintain the intensive margin of activity, with respect to the financial friction free situation. Combining the dynamics of the intensive and extensive margin leads to a better performance of activity, as the marginal increase in the intensive margin is higher than the marginal negative effects of financial frictions on the extensive margin of activity.

\subsection{Price mark-up shock}

Figure 7 depicts the impulse responses following a positive cost push shock. In this situation, the increase in the price of goods has a positive effect on the extensive margin of activity as this increase in selling prices makes new firms' entry more profitable (Equation 40). In the meanwhile, as this increase in inflation leads to an increase of the policy interest rate - through the Taylor rule (Equation 49) - it depresses investment in the economy, which has a negative effect on the intensive margin. Without financial frictions, the decrease in the intensive margin is lower than the increase in the extensive margin, which implies a rise in activity. This dynamics of the GDP is clearly at odds with standard empirical results of the literature, as a positive cost push shock corresponds to a negative supply innovation.

As observed in the Figure 7, the introduction of financial frictions are necessary to fix this consistency problem: now, as wages need to be financed by loans, the policy rate reaction, by making loans more expensive to subscribe, has a damaging effect on firms creation, with respect to the friction free setting. The incentive to enter the goods market is negatively affected by the fact that financing wages during the entering period is more expensive for entrepreneurs. In the meanwhile, the cost of investment is also positively affected. As a consequence, the decrease in the intensive margin of activity is amplified with financial frictions. Combining these two novel dynamics with financial frictions reintroduces a standard effect of the positive cost-push shock on activity by depressing both margins. 


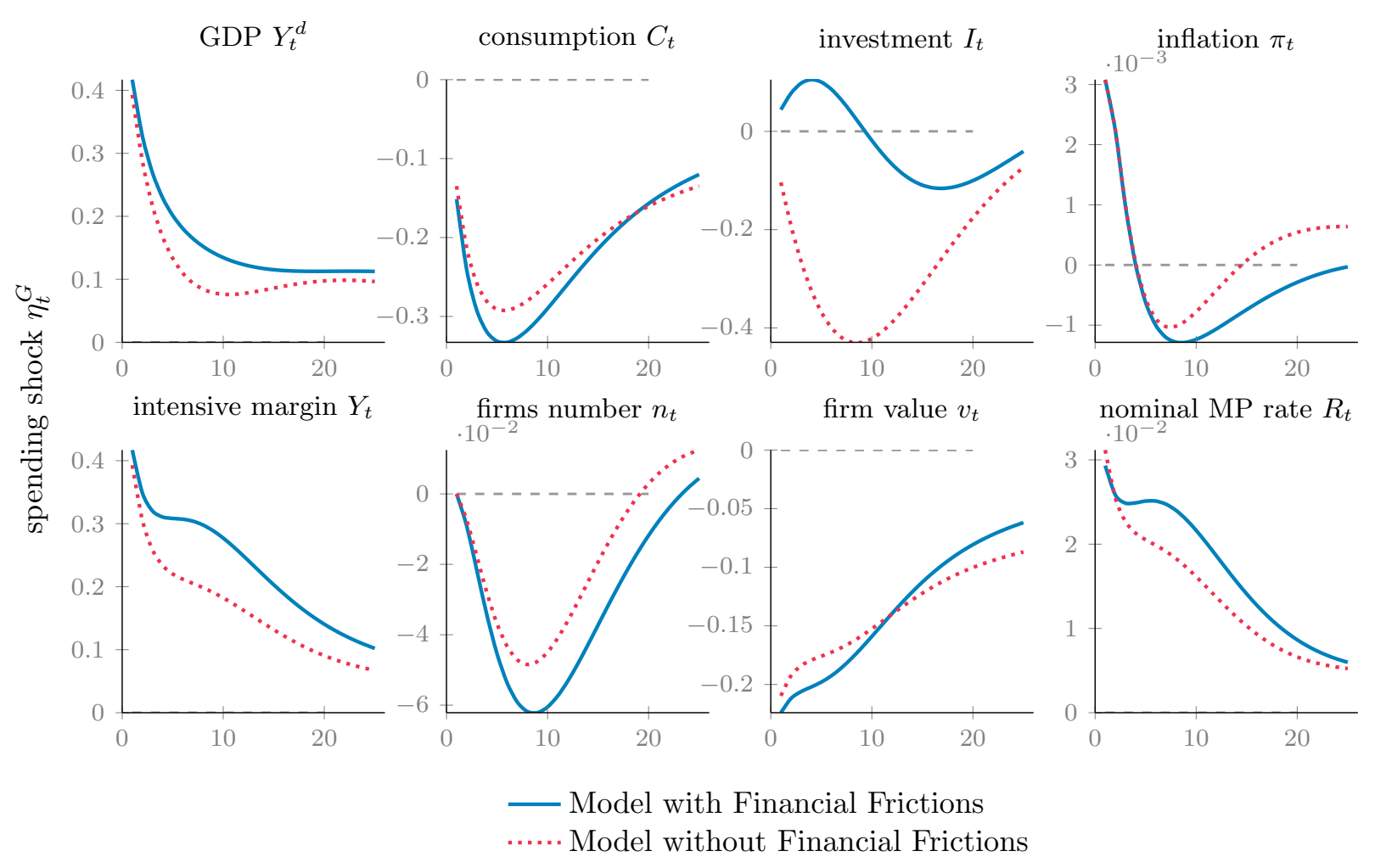

Figure 6: System response to an estimated spending shock $\eta_{t}^{G}$ measured in percentage deviations from steady state with financial frictions (plain blue) and without (dashed red).

Note: These IRFs are obtained classically by calibrating the model at the posterior mean as reported in Table 1 and Table 2.

\subsection{Monetary policy shock}

Finally, Figure 8 depicts the impulse responses of an increase in the policy interest rate (that affects the value of the interest rate shock in Equation 49). As observed financial constraints amplify the negative effect of the shock. By raising the interest rate on loans (Equation 16), this policy leads to a higher cost of new varieties creation, as entrepreneurs should pay more for getting the amount necessary to finance wages in advance for the new production lines as depicted in Equation 1. In this case, as observed, this shock mainly affects the extensive margin of activity. As it becomes less interesting to finance the creation of new varieties, entrepreneurs tend to favour investment in existing firms. Thus, more financial resources are devoted to investment (the decrease in investment is dampened by the arbitrage of entrepreneurs) which has a positive impact on the intensive margin of activity with regards to what is observed in the financial friction free setting. However, combining the dynamics of the extensive and intensive margins leads to more decrease in GDP following the policy shock. As observed, the marginal increase in the intensive margin is lower than the marginal negative effects of financial frictions on the extensive margin of activity. Thus, financial frictions tend to amplify the negative impact 


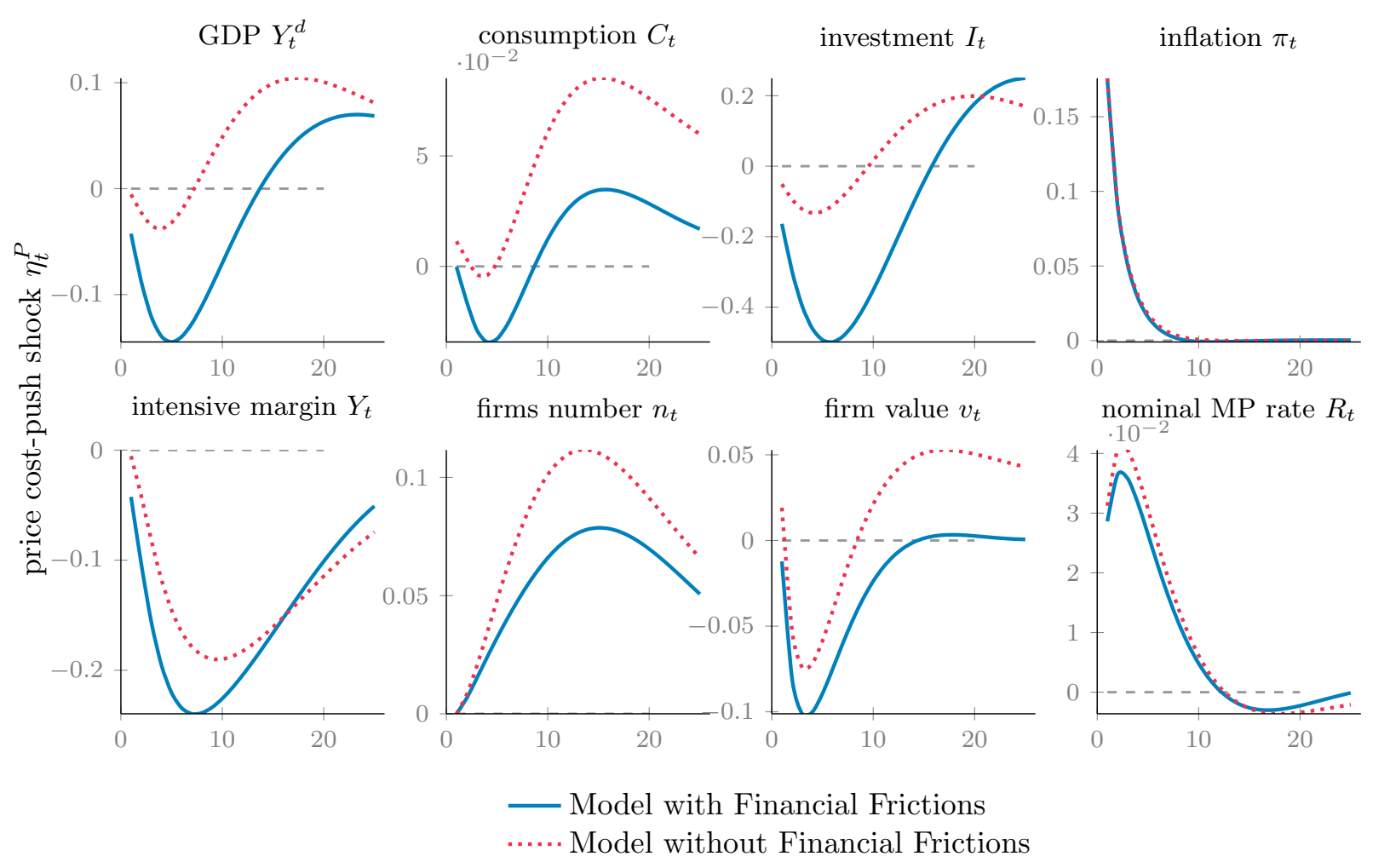

Figure 7: System response to an estimated cost-push shock $\eta_{t}^{P}$ measured in percentage deviations from steady state with financial frictions (plain blue) and without (dashed red).

Note: These IRFs are obtained classically by calibrating the model at the posterior mean as reported in Table 1 and Table 2.

of an increase in the policy rate on activity.

\section{The Propagation of Financial Shocks}

This section analyses the effects of financial shocks on the entry of new firms. We first evaluate the specific consequences of each type of financial shock (affecting the collateral of entrepreneurs or the mark up of the banking system) on the main variables of interest of the model using Bayesian IRFs. In a second subsection we analyse the relative contribution of financial and non-financial shocks to the fluctuations of the extensive margin of activity of US GDP during the sample time period running from 1993Q1 to 2012Q3.

\subsection{Bayesian Impulse Response Analysis}

Figure 9 and Figure 10 depict the Bayesian impulse responses of selected variables to two financial shocks. We report the simulated responses of the main macroeconomic and financial variables following financial shocks equal in size to their standard deviation estimated 


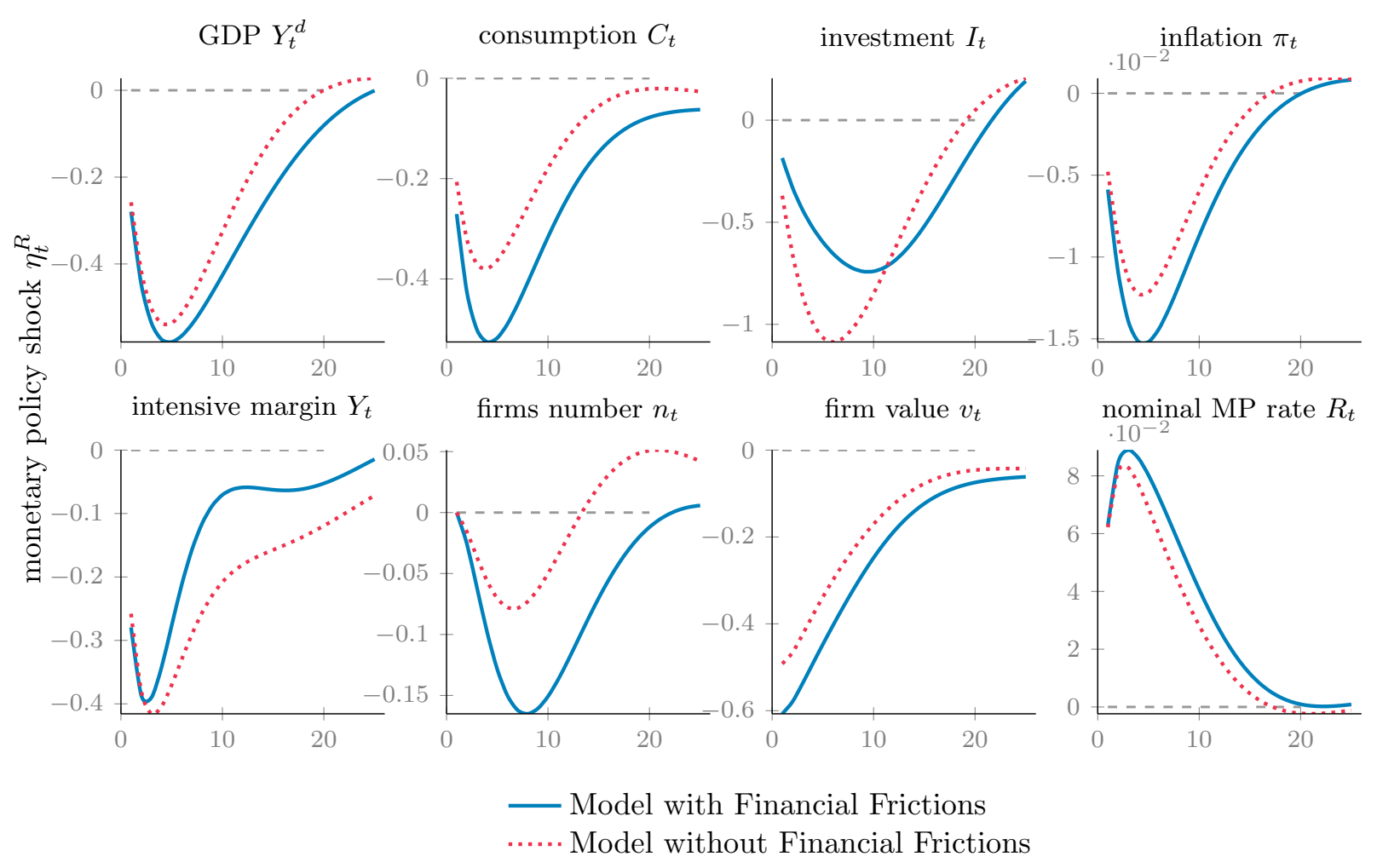

Figure 8: System response to an estimated monetary policy shock $\eta_{t}^{R}$ measured in percentage deviations from steady state with financial frictions (plain blue) and without (dashed red).

Note: These IRFs are obtained classically by calibrating the model at the posterior mean as reported in Table 1 and Table 2.

above. We contrast the consequences of an increase in the net worth of entrepreneurs (that can be associated to an improvement of the stock exchange) and that of an increase in the mark up of banking activity (which deteriorates the lending conditions in the economy).

\subsubsection{A collateral shock}

A positive shock on the collateral (i.e., $\eta_{t}^{N}>0$ ) increases activity, inflation investment and the number of firms as reported in Figure 9. In this situation, the rise in the entrepreneurs' net wealth has two complementary effects on total investment: a direct effect on the total amount of personal resources and an implied effect on the access of entrepreneurs to bank loans, as it allows them to get more loans at a lower interest rate (as observed, the loan on credit $R_{t}^{L}$ decreases following the shock). The rise in financial resources is dispatched between investment and new firms. The entry of new firms is favoured by the increase in their share value coming from the increase in the selling price of goods. Thus, the rise in activity combines the joint rise of the extensive and intensive margins. 

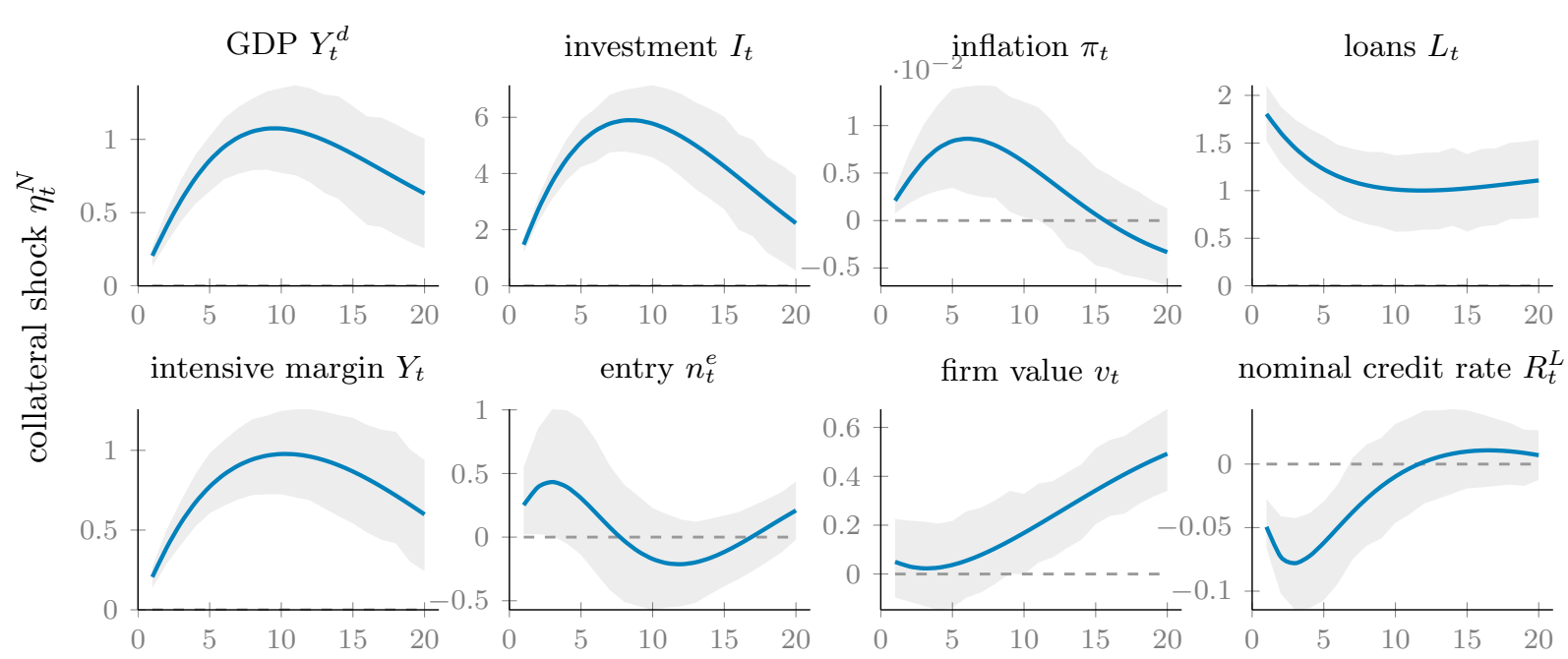

Figure 9: System response to an estimated collateral shock $\eta_{t}^{N}$ measured in percentage deviations from steady state. Mean IRF is reported in blue and 5th and 95th percentiles are reported in grey area.

Note: The blue line is the mean of the distribution of the IRFs generated when parameters are drawn from the posterior distribution as reported in Figure 4.

\subsubsection{A credit rate mark-up shock}

A positive mark-up shock on loan interest rates (i.e., $\eta_{t}^{L}>0$ ) depresses the economy, as shown in Figure 10. This shock corresponds to an exogenous deterioration of the borrowing conditions offered to entrepreneurs. Namely, by increasing the cost of loans to entrepreneurs it depresses both investment in existing firms and in the creation of new varieties. As it reduces firms' profits, this shock diminishes consumption, which combined with the drop in investment reduces the final demand for goods. This induces deflation in the economy which translates into a reduction in the value of firms after 3 quarters. This decrease in firms' value negatively affects the no-arbitrage condition for entry, which decreases the number of new production lines in the economy. Thus the drop in activity combines a decrease in both the intensive and extensive margins.

In contrast with real macroeconomic shocks (where investment in existing production lines and in new firms move in the opposite way, following the arbitrage of entrepreneur regarding the allocation of financial resources between these two competing outcomes) financial shocks appear to be rather destabilizing, as they have a cumulative effect on the two margins of activity.

\subsection{The Contribution of Financial Shocks on the Fluctuations of the Extensive Margin of Activity}

Figure 11 depicts the forecast error variance decomposition for the effective share of entry (namely the ratio between the number of new products to the existing number of products 


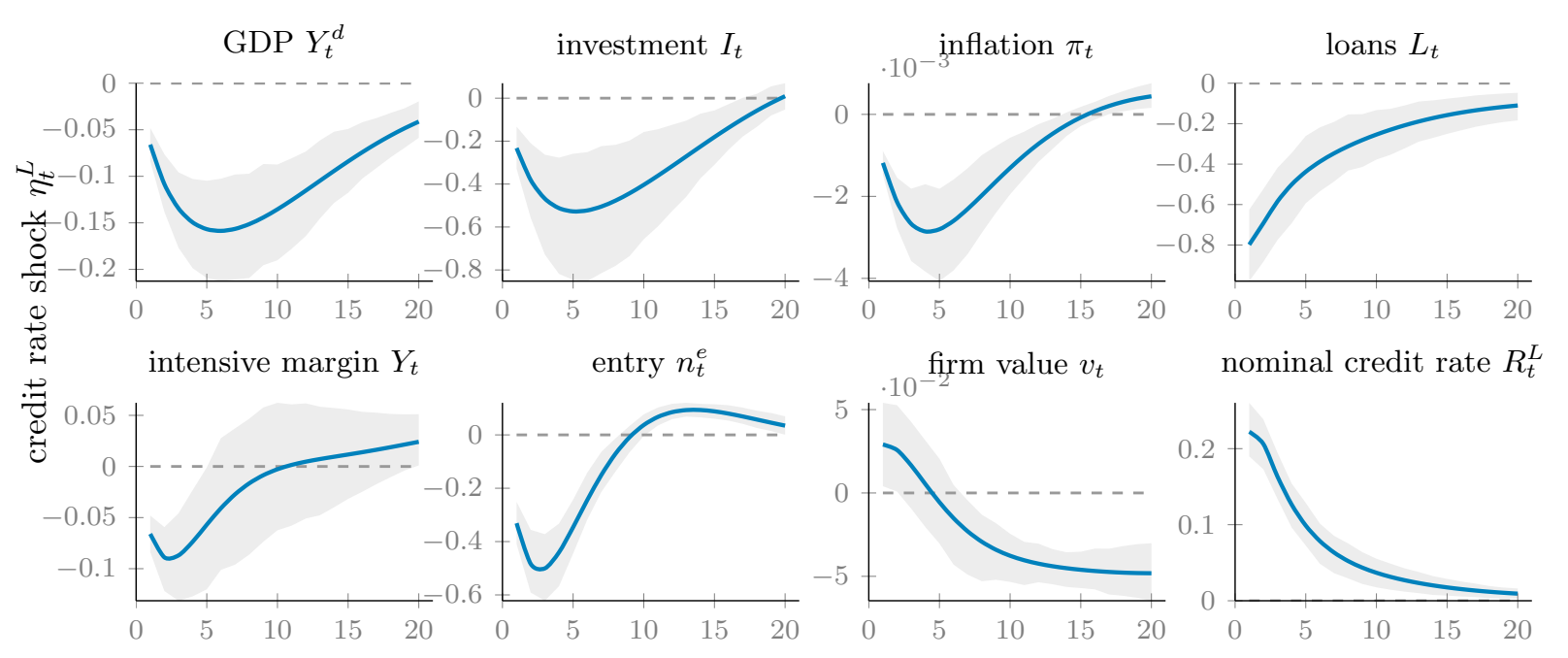

Figure 10: System response to an estimated credit rate shock $\eta_{t}^{L}$ measured in percentage deviations from steady state. Mean IRF is reported in blue and 5th and 95th percentiles are reported in grey area.

Note: The blue line is the mean of the distribution of the IRFs generated when parameters are drawn from the posterior distribution as reported in Figure 4.

on the goods market). We decompose the variance of this ratio between five main components related to financial shocks (Investment, entrepreneurs' net worth and the mark up of lending rate), supply shocks (technology, price and wage mark-up shocks), entry shocks, monetary policy and demand shock (namely spending and premium shocks). We contrast 5 time horizons, raking from one quarter (Q1) to ten years (Q40) and report the unconditional forecast error variance decomposition $(\mathrm{Q} \infty)$.

As observed, the long run effective share of entry variability (at least from Q10 onwards) is mainly explained by a combination of two supply shocks (namely the entry, the technology and the price and wage mark-up shocks) that represent around $70 \%$ of total fluctuation in the ratio. In contrast, the role of financial shocks is rather limited (around 10\%). In the short run, the sources of output fluctuations are more mixed and their relative weight depends on the selected quarter. The very short run (Q1) offers a very original perspective on the driving forces of entry. New firm creation is almost entirely explained by two main factors: financial shocks play a critical role (explaining around $50 \%$ of the variance) and demand shocks. ${ }^{31}$ In the intermediate time horizons (Q2 to Q4), the entry shock critically affects the variance of the effective share of entry. Demand shocks explain around $25 \%$ of the variance in Q2 (its highest contribution over the time horizons presented in the figure) while the contribution of supply shocks is negligible in Q2. One interesting aspect is that financial shocks have a very marginal effect in Q2, showing that financial conditions are mainly important for the entry period, while becoming less interesting for the rest of the analysis.

\footnotetext{
${ }^{31}$ This result is explained by the timing of entry as defined in the original framework of Bilbiie et al. (2007) where new entrants require one period to settle their new business.
} 
Effective Share of Entry

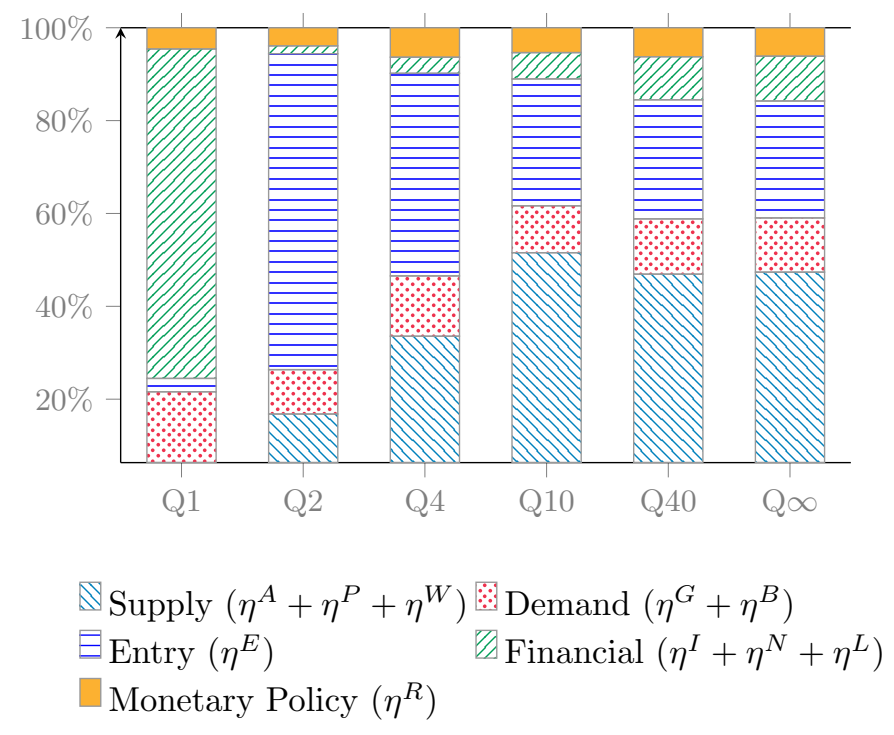

Figure 11: Forecast error variance decomposition at posterior mean for different time horizons (one, two, four, ten, forty and unconditional).

We document in Figure 12 the time path of the effective share of entry on a quarter-onquarter basis. The solid line depicts the time path of the ratio in deviation from the steady state (as reported by the data), while bars depict the size of shocks in the corresponding point deviation. As observed, the explanatory power of the model is quite high (as the darker component in the figure that accounts for other factors not taken into account by the model has only a marginal contribution) and we can link the time path of the ratio to shocks in a rather reliable way.

In Figure 12, we can distinguish between two time periods. First, up to the financial crisis of 2007-2009, the fluctuations in the effective share of entry is rather limited (lying between -5 to $+5 \%$ ). Most of the time the ratio remains positive (we observe only 4 quarters with a negative value over 15 years). Over this time period the relative contribution of demand, supply and financial shocks can be either positive or negative. In contrast, in the second time period, the financial crisis has deeply impacted the net share of entry, as the ratio clearly declines up to $-20 \%$ in 2009 before recovering by the end of the sample period (although it clearly remains negative). The deep negative effect on entry is driven by supply shocks, monetary policy and entry shocks between 2007 and 2009. In contrast, the relative recovery of this ratio after 2009 is driven by monetary policy shocks and (after 2011) by supply shocks. Since the beginning of the financial crisis demand shocks have had a negative contribution on the evolution of the ratio. As observed, the contribution of financial shocks is slightly positive up to 2008, while it has a clear depressing impact on firm entry since 2009. 


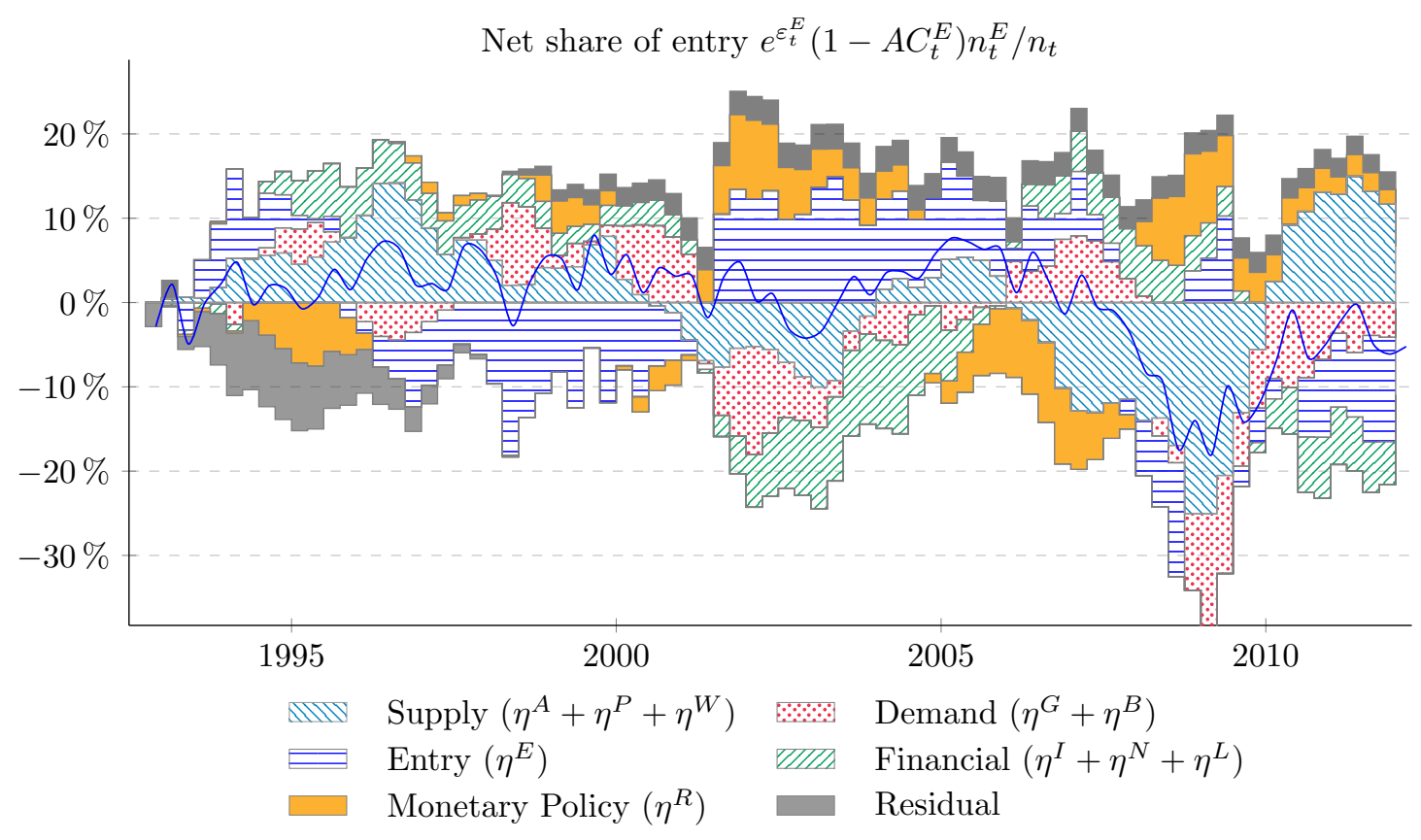

Figure 12: Historical decomposition of the net share of entry.

\section{The importance of the financial dividend policy and of the wage bill in advance}

The model encompasses two financial shocks that are necessary to fit two financial time series in the empirical exercise. However the system response to these two shocks was initially at odds with the data. To fix these issues, we have introduced two new financial frictions which are deemed necessary to replicate the data: a financial dividend redistribution parameter and a wage bill in advance constraint related to the lending conditions of the banking system. This section discusses the key role of these financial frictions with respect to the diffusion of an interest rate shock and a collateral shock.

\subsection{The wage bill in advance}

As reported in Figure 13, the introduction of a standard wage bill in advance constraint (as new firms have to finance a fraction $\gamma$ of their wage bill through loans in Equation 1) offers an interesting solution to fix the problem observed in the original setting of Bilbiie et al. (2007) regarding the counter intuitive consequences of a increase of the interest rate on the number of firms entry. In their setting the creation of new firms is directly linked to the policy rate. They get a counter intuitive result as an increase in the interest rate has a contractionary effect on the number of firms. Their result is explained as follows: An interest rate increase generates deflation and a negative response of GDP and wages. The increase in the number of entrants occurs because no-arbitrage requires the expected return on equity to increase along with the ex ante real return on bonds. The increase in the expected return on equity is brought about by a decrease in the price of shares today 
relative to the future: The procyclical impact response of the real wage translates into a decrease in today's equity price via the free entry condition. The cost of firm creation which requires labour — decreases, and its expected return increases, inducing an increase of the investment in new production lines. This expansionary effect of the increase in the policy rate relies crucially on the link between firm value and the marginal cost implied by free entry.

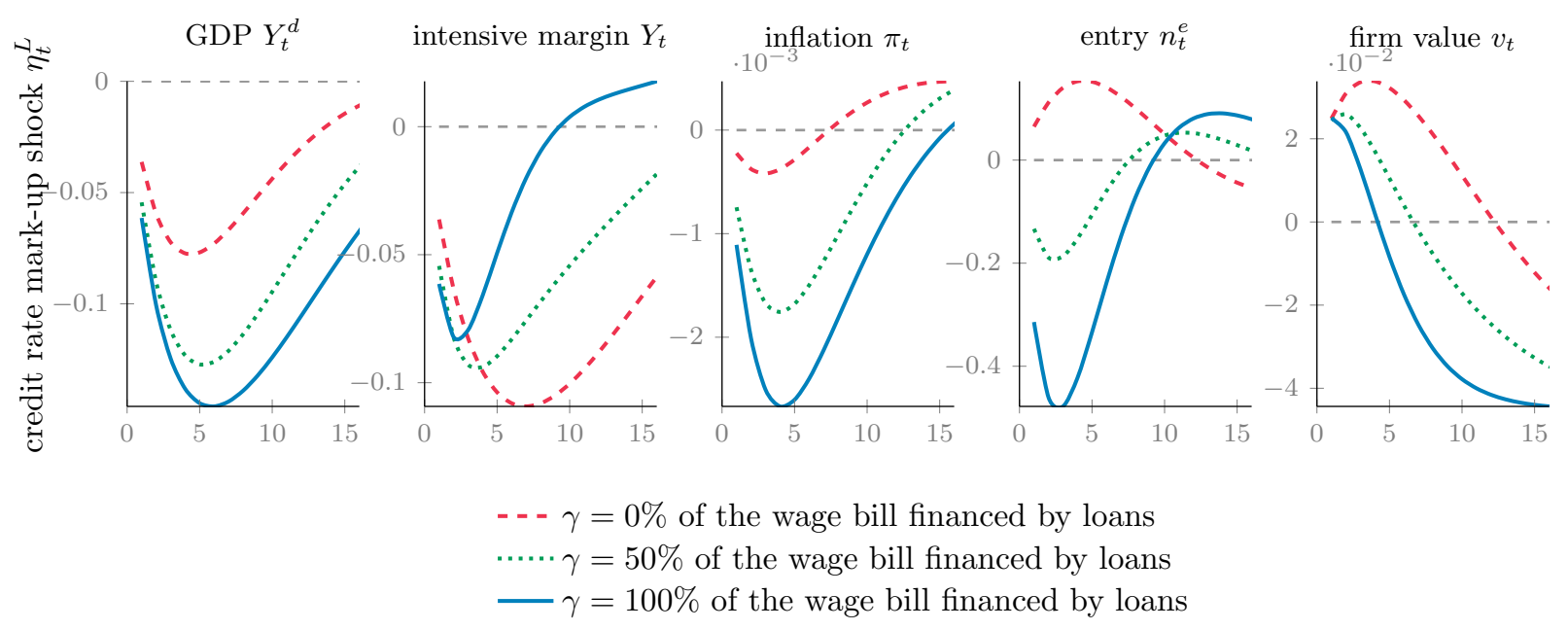

Figure 13: System response to an estimated credit rate mark-up shock $\eta_{t}^{L}$ for various values of $\gamma$ the share of the wage bill financed by loans to produce new firms.

Note: These IRFs are obtained classically by calibrating the model at the posterior mean as reported in Table 1 and Table 2.

In our financial environment the creation of new firms by entrepreneurs depends on an interest rate set by the banking system and no longer on the sole policy rate set by the monetary authorities. Thus what is important is the link between the lending rate and the creation of new firms. To get an intuitive result showing that an increase in this interest rate leads to a decrease in the number of firms we require a positive value for the wage bill parameter. As underlined in Figure 13, we find that if we neglect the wage in advance parameter, we get a similar counter intuitive result as BGM. Introducing the assumption of a wage in advance constraint on the creation of new firms, creates a natural financial channel on the marginal cost of investing in a new variety of goods is an interesting device for getting a more intuitive effect of the interest rate rise on the number of new firms.

As depicted in the fourth panel of Figure 13 the introduction of the wage bill financed by loans succeeds in getting an intuitive impact of loan interest rates on the creation of new firms. As presented, we get a clear negative impact of an increase in the interest rate faced by entrepreneurs that can be explained as follows: entrepreneurs have to pay a higher cost to finance the new production lines. As a consequence, this translates into fewer entries, even for a very small value of the parameter. Indeed, as the cost of firm creation increases, this depresses both the value of firms in the economy and the rate of entry. In contrast, this makes the contribution of the intensive margin to output fluctuations lighter. Finally, 
combining the evolution of the two margins, we find that the depressed impact on the extensive is higher than the dampening of the intensive margin decrease, which translates in a much higher impact of monetary policy decisions on activity. Thus, accounting for financial frictions related to the role of credit decision in the creation of new firms has a higher impact on both inflation and activity.

\subsection{The financial dividend policy}

The second major novelty of our set-up is the possibility for entrepreneurs to distribute a fraction $\theta$ of the dividends to households. As previously noted, this assumption affects the Euler bond equation: the current share price becomes a function of the expected financial dividends which in turn affects the entry condition. A higher value of this parameter makes the decision of households to create new firms more sensitive to the financial soundness of the economy. Figure 14 displays the model response after a collateral shock for various values of $\theta$. Without redistribution, a positive collateral shock boosts investment and output while the lending rate and inflation lower. This price drop depresses expected dividends from firms which in turn diminishes both the share price and the number of entrants. The introduction of a dividend redistribution policy reverses the negative effect on share price. The rise in expected dividends from entrepreneurs increases both the share price and the number of new firms. Indeed, as households take benefits form a higher redistribution of dividends, they tend to increase the value of shares, which in turn leads to an increase in firms' entry.

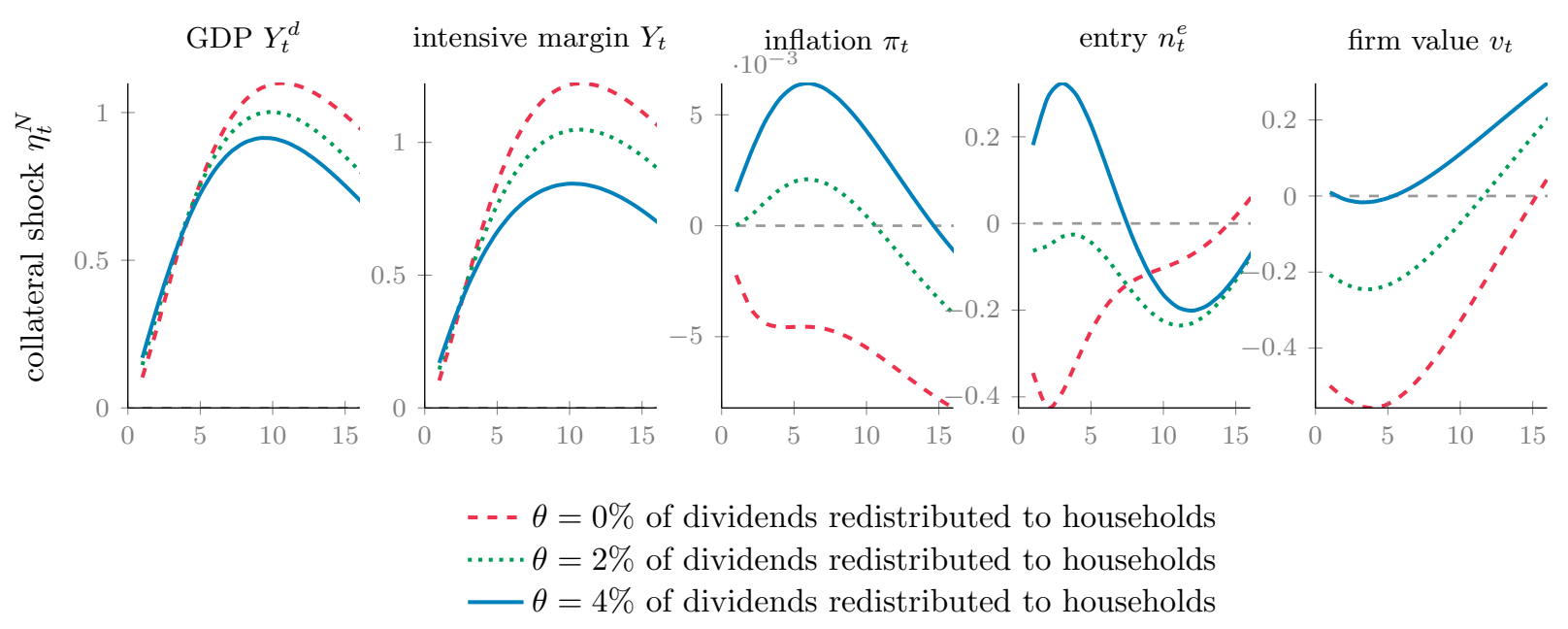

Figure 14: System response to an estimated collateral shock $\eta_{t}^{N}$ for various values of $\theta$ the share of entrepreneurial dividends redistributed to households.

Note: These IRFs are obtained classically by calibrating the model at the posterior mean as reported in Table 1 and Table 2. 


\section{Conclusion}

The aim of this paper was to evaluate the contribution of financial frictions and financial shocks to US output fluctuations using a DSGE model estimated over the sample time period 1993Q1 to 2012Q3, once accounting for the extensive margin and intensive margin of activity. To this aim, we have built a model combining two recent strands of the DSGE literature: models of the extensive margin of activity following the approach initiated by Bilbiie et al. (2007) and models taking into account the financial accelerator. In this setting even if the stock market value of firms still plays a key role in determining the creation of new goods, we have taken into account the fact that creating new production line requires loans from financial intermediaries. We have estimated this setting using recent development of Bayesian econometrics.

We get three main results. First, regarding the analytical contribution to the literature, we find that financial frictions may play a critical role to replicate real word data. In particular, in our setting, we have introduced a wage bill in advance constraint that relates the creation of firms to the lending conditions of the banking system.

Second, in this setting, although the optimal quantity of firm entry is determined by the household optimizing program, the financial resources of entrepreneurs determine in fine the effective rate of new firms creation. The financial constraint - related to the need for entrepreneurs to get loans from the banking system in order to finance investment in existing firms and the creation of new goods' varieties - clearly affects the dynamics of the macroeconomic variables. Thus, in contrast with real macroeconomic shocks (where investment in existing production lines and in new firms move in the opposite way, following the arbitrage of entrepreneur regarding the allocation of financial resources between these two competing outcomes) financial shocks are rather destabilizing, as they have a cumulative effect on the two margins of activity.

Third, the forecast error variance decomposition of the effective share of entry underline the critical role of financial factors mainly in the period following the creation of new firms. In the long run, the effective share of entry variability is mainly explained by supply shocks.

Our analysis has focused on the effect of financial factors on entry. The next step should be to make the rate of firm exit endogenous and related to the financial situation of the firms to provide a broader picture of the effect of financial frictions and financial shocks on the life and death of US enterprises, in particular following the recent financial crisis. 


\section{References}

Adjemian, S., Bastani, H., Karamé, F., Juillard, M., Mihoubi, F., Perendia, G., Pfeifer, J., Ratto, M., Villemot, S., 2014. Dynare: Reference manual, version 4. Tech. rep., Dynare Working Papers 1, CEPREMAP.

Aghion, P., Fally, T., Scarpetta, S., 2007. Credit constraints as a barrier to the entry and post-entry growth of firms. Economic Policy 22 (52), 732-779.

An, S., Schorfheide, F., 2007. Bayesian analysis of dsge models. Econometric reviews 26 (2-4), 113-172.

Beck, T., Levine, R., Loayza, N., 2000. Finance and the sources of growth. Journal of financial economics 58 (1), 261-300.

Bergin, P., Feng, L., Lin, C.-Y., May 2014. Financial frictions and firm dynamics. Working Paper 20099, National Bureau of Economic Research.

URL http://www.nber.org/papers/w20099

Bernanke, B., Gertler, M., Gilchrist, S., 1999. The financial accelerator in a quantitative business cycle framework. Handarticle of macroeconomics 1, 1341-1393.

Bilbiie, F. O., Ghironi, F., Melitz, M. J., June 2007. Monetary policy and business cycles with endogenous entry and product variety. Working Paper 13199, NBER Macroeconomics Annual.

URL http://www.nber.org/papers/w13199

Brooks, S. P., Gelman, A., 1998. General methods for monitoring convergence of iterative simulations. Journal of computational and graphical statistics 7 (4), 434-455.

Casares, M., Poutineau, J.-C., 2013. Firm entry under financial frictions. Review of Development Economics $17(2), 301-318$.

Casares, M., Poutineau, J.-C., 2014. Carleton economic papers. CEP 14, 06.

Chang, Y., Gomes, J. F., Schorfheide, F., 2002. Learning-by-doing as a propagation mechanism. The American Economic Review 92 (5), 1498-1520.

Christiano, L. J., Eichenbaum, M., Evans, C. L., 2005. Nominal rigidities and the dynamic effects of a shock to monetary policy. Journal of political Economy 113 (1), 1-45.

Christiano, L. J., Motto, R., Rostagno, M., 2014. Risk shocks. The American Economic Review 104 (1), $27-65$.

Colciago, A., Etro, F., 2010. Real business cycles with cournot competition and endogenous entry. Journal of Macroeconomics 32 (4), 1101-1117.

Darracq-Pariès, M., Kok-Sørensen, C., Rodriguez-Palenzuela, D., 2011. Macroeconomic propagation under different regulatory regimes: Evidence from an estimated dsge model for the euro area. International Journal of Central Banking 7 (4), 49-113.

De Graeve, F., 2008. The external finance premium and the macroeconomy: Us post-wwii evidence. Journal of Economic Dynamics and Control 32 (11), 3415-3440.

Dixit, A. K., Stiglitz, J. E., 1977. Monopolistic competition and optimum product diversity. The American Economic Review, 297-308.

Etro, F., 2014. The theory of endogenous market structures. Journal of Economic Surveys 28 (5), 804-830.

Faia, E., 2007. Finance and international business cycles. Journal of Monetary Economics 54 (4), 1018-1034. 
Gerali, A., Neri, S., Sessa, L., Signoretti, F. M., 2010. Credit and banking in a dsge model of the euro area. Journal of Money, Credit and Banking 42 (s1), 107-141.

Ghironi, F., Melitz, M. J., 2007. Trade flow dynamics with heterogeneous firms. The American economic review, 356-361.

Greenwood, J., Jovanovic, B., 1990. Financial development, growth, and the distribution of income. Journal of Political Economy, 1076-1107.

Guiso, L., Sapienza, P., Zingales, L., 2004. Does local financial development matter? The Quarterly Journal of Economics 119 (3), 929-969.

Jayaratne, J., Strahan, P. E., 1996. The finance-growth nexus: Evidence from bank branch deregulation. The Quarterly Journal of Economics, 639-670.

La Croce, C., Rossi, L., 2014. Endogenous entry, banking, and business cycle. DEM WORKING PAPER SERIES 72, Department of Economics and Management, University of Pavia.

La Croce, C., Rossi, L., 2015. Firms endogenous entry and monopolistic banking in a dsge model. Macroeconomic Dynamics Forthcoming.

Levine, R., 1997. Financial development and economic growth: views and agenda. Journal of economic literature, $688-726$.

Lewis, V., Poilly, C., 2012. Firm entry, markups and the monetary transmission mechanism. Journal of Monetary Economics 59 (7), 670-685.

Lewis, V., Stevens, A., 2015. Entry and markup dynamics in an estimated business cycle model. European Economic Review 74, 14-35.

Lucas Jr, R. E., Stokey, N., 1985. Money and interest in a cash-in-advance economy.

Peretto, P. F., 1999. Cost reduction, entry, and the interdependence of market structure and economic growth. Journal of Monetary Economics 43 (1), 173-195.

Poutineau, J.-C., Vermandel, G., 2015. Cross-border banking flows spillovers in the eurozone: Evidence from an estimated dsge model. Journal of Economic Dynamics and Control 51, 378-403.

Rossi, L., 2015. Endogenous firms' exit, inefficient banks and business cycle dynamics. DEM WORKING PAPER SERIES 99, Department of Economics and Management, University of Pavia.

Rotemberg, J. J., 1982. Monopolistic price adjustment and aggregate output. The Review of Economic Studies 49 (4), 517-531.

Sadeghi, A., 2008. Births and deaths of business establishments in the united states, the. Monthly Lab. Rev. 131, 3.

Smets, F., Wouters, R., 2003. An estimated dynamic stochastic general equilibrium model of the euro area. Journal of the European economic association 1 (5), 1123-1175.

Smets, F., Wouters, R., 2007. Shocks and frictions in us business cycles: A bayesian dsge approach. American Economic Review 97 (3), 586-606. 


\section{Appendices}

\section{A Data Description and Measurement Equations}

We use a similar sample as Smets and Wouters augmented with two financial time series and one on entry.

- $\mathcal{Y}_{t}$ : Real Gross Domestic Product, 3 Decimal, Billions of Chained 2009 Dollars, Quarterly, Seasonally Adjusted Annual Rate. Sources: Fred database.

- $\mathcal{C}_{t}$ : Personal Consumption Expenditures, Billions of Dollars, Quarterly, Seasonally Adjusted Annual Rate. Sources: Fred database.

- $\mathcal{I}_{t}$ : Fixed Private Investment, Billions of Dollars, Quarterly, Seasonally Adjusted Annual Rate. Sources: Fred database.

- $\mathcal{P}_{t}$ : Gross Domestic Product: Implicit Price Deflator, Index 2009=100, Quarterly, Seasonally Adjusted. Sources: Fred database.

- $\mathcal{R}_{t}$ : Effective Federal Funds Rate, Percent, Quarterly, Not Seasonally Adjusted. Sources: Fred database.

- $\mathcal{W}_{t}^{r}$ : Nonfarm Business Sector: Real Compensation Per Hour, Index 2009=100, Quarterly, Seasonally Adjusted. Sources: Fred database.

- $\mathcal{H}_{t}$ : Nonfarm Business Sector: Average Weekly Hours. Sources: Fred database.

- $\mathcal{S}_{t}$ : Moody's Seasoned Baa Corporate Bond Minus Federal Funds Rate, Seasonally Adjusted Annual Rate. Sources: Fred database.

- $\mathcal{L}_{t}$ : Commercial and Industrial Loans, All Commercial Banks, Billions of U.S. Dollars, Quarterly, Seasonally Adjusted.Sources: Fred database.

- $\mathcal{N}_{t}^{E}$ : Private Sector Establishment Births, Seasonally Adjusted, In thousands. Sources: Bureau of labour Statistics.

Additional series:

- $\mathcal{P} \mathcal{L}_{t}$ : Population Level, Civilian non-institutional population, Number in thousands, 16 years and over. Sources: Fred database.

- $\mathcal{C E}_{t}$ : Civilian Employment, Thousands of Persons, Quarterly, Seasonally Adjusted. Sources : Fred database.

- $\mathcal{X}_{t}$ : Private sector establishment deaths (firm exit), seasonally adjusted (In thousands) Sources: Bureau of labour Statistics. 
We first construct a population and employment indexes in line with year of reference of output, prices and wages (here 2009) such that $\mathcal{P} \mathcal{L}_{t}^{09}=\mathcal{P} \mathcal{L}_{t} / \mathcal{P} \mathcal{L}_{2009}$ and $\mathcal{C} \mathcal{E}_{t}^{09}=\mathcal{C} \mathcal{E}_{t} / \mathcal{C} \mathcal{E}_{2009}$. Following Chang et al. (2002), who point to the limited coverage of the nonfarm business sector compared to GDP, we multiply the index of average hours for the nonfarm business sector (all persons) by civilian employment. Letting $X_{t}^{r}, X_{t}^{l}$ and $\widehat{X}_{t}$ denote the real, the per capita and the in logs value of $X_{t}$ respectively, the per capita transformed series taken in logs becomes: $\widehat{\mathcal{H}}_{t}^{l}=100 \log \left(\mathcal{H}_{t} \mathcal{C} \mathcal{E}_{t}^{09} / \mathcal{P} \mathcal{L}_{t}^{09}\right)$. We also set in real terms/per capita/logs the output $\widehat{\mathcal{Y}}_{t}^{r l}=100 \log \left(\mathcal{Y}_{t} / \mathcal{P} \mathcal{L}_{t}^{09} / \mathcal{P}_{t}\right)$, consumption $\widehat{\mathcal{C}}_{t}^{r l}=100 \log \left(\mathcal{C}_{t} / \mathcal{P} \mathcal{L}_{t}^{09} / \mathcal{P}_{t}\right)$, investment $\widehat{\mathcal{I}}_{t}^{r l}=100 \log \left(\mathcal{I}_{t} / \mathcal{P} \mathcal{L}_{t}^{09} / \mathcal{P}_{t}\right)$ and loans $\widehat{\mathcal{L}}_{t}^{r l}=100 \log \left(\mathcal{L}_{t} / \mathcal{P} \mathcal{L}_{t}^{09} / \mathcal{P}_{t}\right)$. Finally for entry, we assume as in the model an exit rate of $2.5 \%$, then we generate $\mathcal{N}_{t}$ the total number of firms using entry and exit series from the bureau of labour statistics. The log share of entry is then $\widehat{\mathcal{N}}_{t}^{E}=100 \log \left(\mathcal{N}_{t}^{E} / \mathcal{N}_{t}\right)$. Finally, we also set in $\operatorname{logs}$ prices $\hat{\mathcal{P}}_{t}=100 \log \left(\mathcal{P}_{t}\right)$ and real wages $\widehat{\mathcal{W}}_{t}^{r}=100 \log \left(\mathcal{W}_{t}^{r}\right)$.

Letting $\Delta X_{t}$ denote the temporal difference of $X_{t}$, the vector of observable can be summarized:

$$
y_{t}^{o b s}=\left[\begin{array}{llllllllll}
\Delta \widehat{\mathcal{Y}}_{t}^{r l} & \Delta \widehat{\mathcal{C}}_{t}^{r l} & \Delta \widehat{\mathcal{I}}_{t}^{r l} & \widehat{\mathcal{H}}_{t}^{l} & \Delta \hat{\mathcal{P}}_{t} & \Delta \widehat{\mathcal{W}}_{t}^{r} & \mathcal{R}_{t} / 4 & \mathcal{S}_{t} / 4 & \Delta \widehat{\mathcal{L}}_{t}^{r l} & \widehat{\mathcal{N}}_{t}^{E}
\end{array}\right]^{\prime}
$$

where series $\mathcal{R}_{t}$ and $\mathcal{S}_{t}$ are set on a quarterly basis by dividing them by 4 . The measurement equations are defined by:

$$
\begin{aligned}
& y_{t}^{m}=\left[\begin{array}{llllll}
\log \left(\frac{Y_{t}^{d}}{Y_{t-1}^{d}}\right) & \log \left(\frac{C_{t}}{C_{t-1}}\right) & \log \left(\frac{I_{t}}{I_{t-1}}\right) & \log \left(H_{t}\right) & \log \left(\pi_{t}^{C}\right) & \log \left(\frac{w_{t}}{w_{t-1}}\right)
\end{array} R_{t}\right. \\
& \left.\frac{1+R_{t}^{L}}{1+R_{t}} \log \left(\frac{L_{t+1}}{L_{t}}\right) \quad \log \left(\frac{n_{t}}{n_{t-1}(1-\delta)}-1\right)\right]^{\prime}
\end{aligned}
$$

Here, we rearranged the law of motion of firms in Equation 20 to get the effective number of firms entering the market.

Since we don't use the information contained in the mean of the observable matrix, we put the model to the data assuming:

$$
y_{t}^{o b s}-E\left[y_{t}^{o b s}\right]=y_{t}^{m}-E\left[y_{t}^{m}\right]
$$

where $E\left[y_{t}^{o b s}\right]$ is the empirical mean and $E\left[y_{t}^{m}\right]$ is the theoretical one (i.e. the steady state of measurements equations).

\section{B Model Summary}

\section{B.1 Non-linear model}

\section{B.1.1 Households}

The marginal utility of consumption can be expressed as:

$$
\lambda_{t}^{c}=\left(C_{t}-h C_{t-1}\right)^{-\sigma_{C}}
$$


The Euler deposit condition on deposits is:

$$
\beta \mathbb{E}_{t}\left\{\frac{\lambda_{t+1}^{c}}{\lambda_{t}^{c}}\right\} e^{\varepsilon_{t}^{B}}\left(1+r_{t}\right)=1
$$

The Euler equation on share is:

$$
v_{t}=(1-\delta) \beta \mathbb{E}_{t}\left\{\frac{\lambda_{t+1}^{c}}{\lambda_{t}^{c}}\left(d_{t+1}+v_{t+1}+\theta d_{t+1}^{E}\right)\right\} .
$$

The labour supply equation is:

$$
\lambda_{t}^{c} w_{t}^{h}=\chi H_{j t}^{\sigma_{H}}
$$

The free entry equation is determined by:

$$
f_{E} m c_{t}^{E}=v_{t} \frac{\partial\left(1-A C_{t}^{E}\right) n_{t}^{E}}{\partial n_{t}^{E}} e^{\varepsilon_{t}^{E}}+\beta \mathbb{E}_{t}\left\{v_{t+1} \frac{\partial\left(1-A C_{t+1}^{E}\right)}{\partial n_{t}^{E}} n_{t+1}^{E} e^{\varepsilon_{t+1}^{E}}\right\}
$$

\section{B.1.2 Unions}

The optimal wage setting is determined by:

$$
\frac{W_{t}}{P_{t}^{C}}=\mu_{t}^{W} \frac{W_{t}^{h}}{P_{t}^{C}}-\left(\mu_{t}^{W}-1\right) W_{t}\left[A C_{t}^{W \prime}+\beta \mathbb{E}_{t}\left\{\frac{\lambda_{t+1}^{c}}{\lambda_{t}^{c}} \frac{H_{t+1}}{H_{t}} A C_{t+1}^{W \prime}\right\}\right]
$$

\section{B.1.3 Installed Firms}

The production function is defined by:

$$
n_{t} Y_{t}=e^{\varepsilon_{t}^{A}}\left(K_{t+1}^{u}\right)^{\alpha}\left(H_{t}^{d}\right)^{1-\alpha}
$$

The utilized capital involved in the production is reads:

$$
K_{i+1}^{u}=u_{t} K_{t}
$$

the real marginal cost expression:

$$
m c_{t}=\frac{1}{e^{\varepsilon_{t}^{A}}}\left(\frac{z_{t}}{\alpha}\right)^{\alpha}\left(\frac{w_{t}}{(1-\alpha)}\right)^{(1-\alpha)} .
$$

From the cost minimization problem, inputs also satisfy:

$$
\alpha H_{t}^{d} w_{t}=(1-\alpha) K_{t+1}^{u} z_{t}
$$

The relative price is set as a mark-up over the marginal cost of production:

$$
\rho_{t}=\mu_{t} m c_{t}
$$


where the endogenous mark-up $\mu_{i t}$ is computed in the following way:

$$
\mu_{t}=e^{\varepsilon_{t}^{P}} \frac{\epsilon_{P}}{\left(\epsilon_{P}-1\right)\left(1-\frac{P_{t}^{C}}{P_{t}} A C_{t}^{P}\right)+\kappa_{P} \Psi_{t}},
$$

and:

$$
\Psi_{t}=\left(\pi_{t}-\left[\xi_{P} \pi_{t-1}+\left(1-\xi_{P}\right)\right]\right) \pi_{t}-\beta \mathbb{E}_{t}\left\{\frac{\lambda_{t+1}^{c}}{\lambda_{t}^{c}}\left(\left(\pi_{t}-\left[\xi_{P} \pi_{t-1}+\left(1-\xi_{P}\right)\right]\right) \pi_{t+1} \frac{Y_{t+1}}{Y_{t}}\right)\right\}
$$

The profit of firms $i$ is determined by:

$$
d_{t}=\left(\rho_{t}-m c_{t}-A C_{t}^{P}\right) Y_{t}
$$

\section{B.1.4 Startups}

The production technology of new goods is:

$$
n_{t}^{E} f_{E}=e^{\varepsilon_{t}^{A}} H_{t}^{E}
$$

the marginal cost of producing a new firm is:

$$
m c_{t}^{E}=\frac{w_{t}}{e^{\varepsilon_{t}^{A}}}\left(1+\gamma r_{t}^{L}\right)
$$

\section{B.1.5 Entrepreneurs}

The balance sheet of entrepreneurs is:

$$
L_{t+1}+N W_{t+1}=Q_{t} K_{t+1}+\gamma W_{t} H_{t}^{E}
$$

The cutoff point is:

$$
\omega_{t}^{C}\left(1+r_{t}^{k}\right) Q_{t-1} K_{t}=\left(1+r_{t-1}^{L}\right) L_{t} .
$$

The external finance premium can be expressed as:

$$
\frac{1+\mathbb{E}_{t} r_{t+1}^{k}}{1+r_{t}^{L}}=\frac{\kappa-1}{\kappa \bar{\omega}^{C}}\left[\frac{\kappa}{\kappa-1}\left(\frac{L_{t+1}}{Q_{t} K_{t+1}}\right)\right]^{\varkappa}
$$

The law of motion of entrepreneurs' net wealth is:

$$
N W_{t+1}=(1-\delta)(1-\theta) d_{t}^{E}+T^{E}
$$

The entrepreneurial dividends are:

$$
n_{t} d_{t}^{E}=\eta_{t}\left(\bar{\omega}_{t}-\omega_{t}^{C}\right)\left(1+R_{t}^{k}\right) Q_{t-1} K_{t} e^{\varepsilon_{t}^{N}}
$$




\section{B.1.6 Financial Intermediaries}

The marginal cost of one unit of loans is:

$$
1+M C_{t}^{L}=\left(1+R_{t}\right) \mathbb{E}_{t}\left[\eta_{t+1}+\left(1-\mu^{B}\right)\left(1-\eta_{t+1}\right) \frac{\underline{\omega}_{t+1}}{\omega_{t+1}^{C}}\right]^{-1}
$$

The nominal lending rate is:

$$
R_{t}^{L}=\mu_{t}^{L} M C_{t}^{L}-\left(\mu_{t}^{L}-1\right) R_{t}^{L}\left(\frac{\partial A C_{t}^{L}}{\partial R_{t}^{L}}+\beta \mathbb{E}_{t}\left\{\frac{\lambda_{t+1}^{c}}{\lambda_{t}^{c}} \frac{\partial A C_{t+1}^{L}}{\partial R_{t}^{L}} \frac{L_{t+2}}{L_{t+1}}\right\}\right)
$$

And we set in real terms the lending rate:

$$
1+r_{t}^{L}=\frac{1+R_{t}^{L}}{\mathbb{E}_{t} \pi_{t+1}^{C}}
$$

\section{B.1.7 Capital Suppliers}

The law of motion of capital reads as follows:

$$
K_{t+1}=e^{\varepsilon_{t}^{I}}\left(1-A C_{t}^{I}\right) I_{t}+(1-\delta) K_{t}
$$

The shadow value of one unit of capital is given by:

$$
\varepsilon_{t}^{I} q_{t}=1+e^{\varepsilon_{t}^{I}} q_{t} \frac{\partial\left(I_{k t} A C_{k t}^{I}\right)}{\partial I_{k t}}+\beta \mathbb{E}_{t}\left\{\frac{\lambda_{t+1}^{c}}{\lambda_{t}^{c}} e^{\varepsilon_{t+1}^{I}} \pi_{t+1}^{C} q_{t+1} \frac{\partial\left(I_{k t+1} A C_{k t+1}^{I}\right)}{\partial I_{k t}}\right\} .
$$

The optimal utilization rate of capital is determined by: ${ }^{32}$

$$
z_{t}=\bar{Z} e^{\psi /(1-\psi)\left(u_{t}-1\right)}
$$

The profitability of one unit of capital is:

$$
1+r_{t}^{k}=\frac{z_{t} u_{t}-\Phi\left(u_{t}\right)+(1-\delta) q_{t}}{q_{t-1}}
$$

\section{B.1.8 Equilibrium conditions}

The Taylor rule is:

$$
R_{t}-\bar{R}=\rho\left(R_{t-1}-\bar{R}\right)+\left(1-\rho_{R}\right)\left[\phi_{\pi}\left(\pi_{t}-1\right)+\phi_{Y}\left(Y_{t}-\bar{Y}\right)\right]+\phi_{\Delta Y}\left(Y_{t}-Y_{t-1}\right)+\varepsilon_{t}^{R}
$$

And the real interest rate is:

$$
1+r_{t}=\frac{1+R_{t}}{\mathbb{E}_{t} \pi_{t+1}^{C}}
$$

\footnotetext{
${ }^{32}$ The problem faced by capital suppliers when choosing the optimal utilization rate is : $\min _{u_{t}} P_{t}^{C} \Phi\left(u_{t}\right) K_{t}-Z_{t} u_{t} K_{t}$.
} 
The total demand in the economy follows:

$$
Y_{t}^{d}=C_{t}+I_{t}+\bar{G} \varepsilon_{t}^{G}+\Phi\left(u_{t}\right) K_{t-1}+n_{t} A C_{t}^{P} Y_{t}+A C_{t}^{W} H_{t}+A C_{t}^{L} L_{t+1}
$$

The relative price $\rho_{t}=P_{t} / P_{t}^{C}$ is:

$$
n_{t} \rho_{t}^{1-\epsilon_{P}}=1
$$

The inflation rate of consumption goods $\pi_{t}^{C}$ accordingly:

$$
\frac{\rho_{t}}{\rho_{t-1}}=\frac{\pi_{t}}{\pi_{t}^{C}}
$$

The market equilibrium on the good market is determined by:

$$
n_{t} Y_{t}=\rho_{t}^{-\epsilon_{P}} Y_{t}^{d}
$$

And the labour market is:

$$
H_{t}=H_{t}^{d}+H_{t}^{E}
$$

Finally, the law of motion of firms is:

$$
n_{j t}=(1-\delta)\left(n_{j t-1}+e^{\varepsilon_{t-1}^{E}}\left(1-A C_{j t-1}^{E}\right) n_{j t-1}^{E}\right)
$$

\section{B.2 Steady state}

\section{B.2.1 The Financial Contract}

First, we can solve the financial contract in steady state. First with $\beta=.0 .992$ and zero inflation in steady state $\bar{\pi}^{C}=\bar{\pi}=1$, the real interest rate using the Euler bond Equation 63 is: $\bar{r}=\bar{R}=\beta^{-1}-1$. We deduct the lending rate using our calibration, $\bar{R}^{L}=\bar{r}^{L}=(1+0.98 / 100) \bar{R}-1$.

Concerning the Pareto distribution $\omega \sim \mathcal{P}\left(\kappa ; \omega_{\text {min }}\right)$, parameter $\kappa$ is the shape parameter and $\omega_{\min }$ the minimum value of $\omega \in\left[\omega_{\min } ;+\infty\right)$ and $\omega$ is the endogenous risk of investment project. The minimum value of $\omega$ corresponds to a frictionless economy, such that there is no risk in the economy (i.e. the default rate is 0 and there is no spread $\bar{r}^{L}=\bar{r}^{k}$ ). First, assuming a $50 \%$ entrepreneurial leverage ratio $\bar{L} / \bar{K}=0.50$ and using the endogenous threshold Equation 78, the value of the minimum bound is:

$$
\omega_{\min }=\bar{L} / \bar{K}=0.50 \text {. }
$$

Second, the first order condition of entrepreneurs in steady state implies, $\left(1+\bar{r}^{k}\right) /\left(1+\bar{r}^{L}\right)=$ $(\kappa-1) /\left(\kappa \bar{\omega}^{C}\right)$, and in a riskless situation it becomes, $1=(\kappa-1) /\left(\kappa \omega_{\min }\right)$, then we obtain the shape of the Pareto distribution:

$$
\kappa=1 /\left(1-\omega_{\min }\right)=\bar{K} / \bar{L}=2 .
$$

Following Bernanke et al. (1999), the steady state entrepreneurs' default rate is set at $2.5 \%$ on an annual basis, $1-\bar{\eta}=2.5 / 400$. The Pareto distribution implies that the survival rate is, $\bar{\eta}=\operatorname{Pr}\left[\omega \geq \bar{\omega}^{C}\right]=\left(\omega_{\min } / \bar{\omega}^{C}\right)^{\kappa}$, from this definition we obtain $\bar{\omega}^{C}$ :

$$
\bar{\omega}^{C}=\omega_{\min } \bar{\eta}^{-\kappa}
$$


and the profitability of one unit of capital is determined by the endogenous cut-off point Equation 78:

$$
\bar{r}^{K}=\frac{\left(1+\bar{r}^{L}\right)}{\bar{\omega}^{C}}\left(1-\frac{\bar{L}}{\bar{K}}\right)-1
$$

and the marginal product of capital $\bar{z}$ defined by Equation 87 is:

$$
\bar{z}=r^{k}+\delta
$$

where $\bar{q}=\bar{u}=1$ and $\Phi(\bar{u})=0$. We are now able to deduct the steady state marginal cost of credit. To compute it, we use statistical properties of the conditional mean, as $\overline{m c}^{L}$ involves the conditional mean of defaulting investment projects $\underline{\omega}$. First as in Bernanke et al. (1999), the expected value is normalized, $E[\omega]=1$. Since we know the value of profitable investment project, $\bar{\omega}=\frac{\kappa}{\kappa-1} \bar{\omega}^{C}$, we can obtain its negative counterpart as the conditional mean verifies:

$$
E[\omega]=1=\bar{\eta} \bar{\omega}+(1-\bar{\eta}) \underline{\omega}
$$

Then we obtain:

$$
\underline{\omega}=\frac{(1-\bar{\eta} \bar{\omega})}{(1-\bar{\eta})}
$$

Then we obtain,

$$
\overline{m c}^{L}=(1+\bar{r})\left[\bar{\eta}+\left(1-\mu^{B}\right)(1-\bar{\eta}) \frac{\underline{\omega}}{\bar{\omega}^{C}}\right]^{-1}-1
$$

Then the mark-up on loans is:

$$
\mu_{L}=\frac{\bar{r}^{L}-1}{\overline{m c}^{L}-1}
$$

\section{B.2.2 The Number of Firms}

Obtaining the steady state number of firms is critical for models with entry and the presence of financial frictions complicates its computation. We first start with Equation 64, the Euler shares equation:

$$
\frac{1-(1-\delta) \beta}{(1-\delta) \beta} \bar{v}=\bar{d}+\theta \bar{d}^{E}
$$

where $\bar{d}, \bar{d}^{E}$ and $\bar{v}$ are going to be replaced in the next step. First concerning Equation 74 of $\bar{d}$, we replace $\overline{m c}=\bar{\rho} / \bar{\mu}$ using Equation 72 , dividends now are given by, $\bar{d}=\bar{Y} \bar{\rho}(\bar{\mu}-1) / \bar{\mu}$. Second turning to $\bar{d}^{E}$, we have $\bar{d}^{E}=\frac{\bar{\eta} \bar{\omega}^{C}}{\kappa-1}\left(1+\bar{r}^{k}\right) \frac{\bar{K}}{\bar{n}}$ from Equation 80 with $\bar{q}=1$. Third, the free entry condition defined by Equation 66 can be expressed as, $\bar{v}=f_{E} \overline{m c}^{E}$ which can be rewritten replacing $\overline{m c}^{E}$ from Equation 76 , now we obtain, $\bar{v}=f_{E} \bar{w}\left(1+\gamma \bar{r}^{L}\right)$. We can rearrange Equation 105 to get:

$$
\frac{1-(1-\delta) \beta}{(1-\delta) \beta} f_{E} \bar{w}\left(1+\gamma \bar{r}^{L}\right)=\bar{Y} \bar{\rho} \frac{(\bar{\mu}-1)}{\bar{\mu}}+d^{K} \frac{\bar{K}}{\bar{n}}
$$

where $d^{K}=\theta \bar{\eta} \bar{\omega}^{C}(\kappa-1)^{-1}\left(1+\bar{r}^{k}\right)$. Using the first order conditions of installed firms, the marginal product of capital is, $\bar{z}=\alpha \bar{n} \bar{Y} \overline{m c} / \bar{K}$, and labour, $\bar{w}=(1-\alpha) \bar{n} \bar{Y} \overline{m c} / \bar{H}^{d}$. 
With $\overline{m c}=\bar{\rho} / \bar{\mu}$, the steady state value of $\bar{K}$ is, $\bar{K}=\alpha \bar{n} \bar{Y} \bar{\rho} /(\bar{z} \bar{\mu})$, and the real wage is $\bar{w}=(1-\alpha) \bar{n} \bar{Y} \bar{\rho} /\left(\bar{H}^{d} \bar{\mu}\right)$. Replacing $\bar{w}$ and $\bar{K}$ in Equation 106 leads to:

$$
\frac{1-(1-\delta) \beta}{(1-\delta) \beta} f_{E}(1-\alpha) \frac{\bar{n}}{\bar{H}^{d}}\left(1+\gamma \bar{r}^{L}\right)=(\bar{\mu}-1)+d^{K} \frac{\alpha}{\bar{z}} .
$$

Finally to get $\bar{n}$ from Equation 106, we needs to rewrite $\bar{H}^{d}$. The labour market equilibrium defined by Equation 94 is, $\bar{H}=\bar{H}^{d}+\bar{H}^{E}$, where $\bar{H}=1 / 3$. The production function of startup as detailed in Equation 75 , is in steady state, $\bar{n}^{E} f_{E}=\bar{H}^{E}$. Using in steady state the law of motion of firms of Equation $95, \bar{n}^{E}=\bar{n} \delta /(1-\delta)$, the demand from startups production is, $\bar{H}^{E}=f_{E} \bar{n} \delta /(1-\delta)$. Thus we can replace $\bar{H}^{d}$ :

$$
\frac{1-(1-\delta) \beta}{(1-\delta) \beta} f_{E}(1-\alpha) \frac{\bar{n}}{\bar{H}-f_{E} \frac{\delta}{(1-\delta)} \bar{n}}\left(1+\gamma \bar{r}^{L}\right)=(\bar{\mu}-1)+d^{K} \frac{\alpha}{\bar{z}} .
$$

Gathering $\bar{n}$, the steady state amount of firms is:

$$
\bar{n}=\bar{H}\left[\frac{(1-(1-\delta) \beta) f_{E}(1-\alpha)\left(1+\gamma \bar{r}^{L}\right)}{(1-\delta) \beta\left((\bar{\mu}-1)+d^{K} \frac{\alpha}{\bar{z}}\right)}+f_{E} \frac{\delta}{(1-\delta)}\right]^{-1}
$$

where $d^{K}=\theta \bar{\eta} \bar{\omega}^{C}(\kappa-1)^{-1}\left(1+\bar{r}^{k}\right)$.

Assuming no financial frictions (such that, $\gamma=\theta=0$ ) and normalizing to one the entry cost $f_{E}=1$, the number of firms is close to Bilbiie et al. (2007). ${ }^{33}$

Our model delivers a number of firms of $\bar{n}=1.0726$, which is lower than the value obtained by Bilbiie et al. (2007). As reported in Figure 15, this result is mainly explained by higher entry costs. The left hand side panel depicts the interaction between the sunk cost $f_{E}$, the number of firms $\bar{n}$ and the investment-to-gdp ratio $\bar{I} / \bar{Y}^{d}$. In our setting high sunk costs are deemed necessary to get an investment-to-gdp ratio consistent with the data (at the expense of the number of firms).

The middle and right hand side panels of Figure 15 depict the effects of financial frictions on the steady state number of firms: As observed, the entrepreneurial dividend policy encourages firms to enter the market while the wage bill in advance constraint has the opposite effect.

\section{B.2.3 The rest of the steady state}

It is now straightforward to get the steady state of the model. First, the relative price from Equation 91 and marginal cost of goods are:

$$
\bar{\rho}=\bar{n}^{\frac{1}{\epsilon_{P}-1}} \text { and } \overline{m c}=\bar{\rho} / \bar{\mu}
$$

And the number of entrants:

$$
\bar{n}^{E}=\bar{n} \frac{\delta}{(1-\delta)}
$$

\footnotetext{
${ }^{33}$ The gap between Bilbiie et al. (2007) and our set-up is explained by the utility function, we introduce a shift parameter $\chi$ for labour in the utility function as Christiano et al. (2014) which allows us to calibrate the steady state amount of hours worked $\bar{H}$.
} 

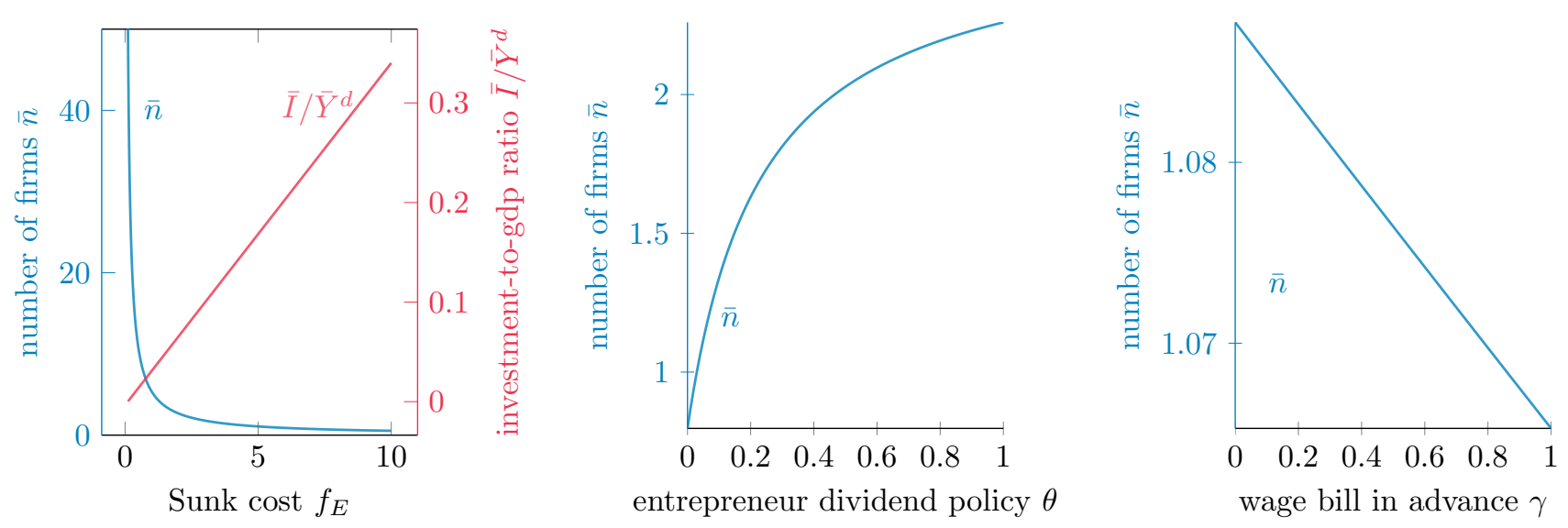

Figure 15: The steady state number of firms, according to the calibration of the sunk cost $f_{E}$, the dividend policy $\theta$ and the wage bill in advance constraint $\gamma$.

The labour demand from both entrants and installed:

$$
\bar{H}^{E}=f_{E} \bar{n} \frac{\delta}{(1-\delta)} \text { and } \bar{H}^{d}=\bar{H}-\bar{H}^{E}
$$

We obtain the real wage using the steady state marginal cost from Equation 70:

$$
\bar{w}=(1-\alpha)\left[\overline{m c}\left(\frac{\alpha}{\bar{z}}\right)^{\alpha}\right]^{1 /(1-\alpha)}
$$

Since capital utilization is normalized in steady state $\bar{u}=1$, then $\bar{K}^{u}=\bar{K}$, the amount of capital in the economy is using Equation 71:

$$
\bar{K}=\frac{\alpha}{\bar{z}(1-\alpha)} \bar{H}^{d} \bar{w}
$$

The rest of the steady state is now straightforward to obtain. Our estimated DSGE model delivers the following steady state for the main variables of interest: $\bar{r}=0.0081, \bar{r}^{L}=$ $0.0179, \mu_{L}=2.1248, \bar{n}=1.0726, \bar{\rho}=1.0254, \bar{K}=5.6037, \bar{r}^{k}=0.0154, \bar{\omega}^{C}=0.5013$, $\bar{Y}=0.6983, \bar{Y}^{d}=0.8238$ and $\bar{C}=0.5354$. 